\title{
Application of Coal Gangue as a Coarse Aggregate in Green Concrete Production: A Review
}

\author{
Shan Gao ${ }^{1,2, *}$, Sumei Zhang ${ }^{1}$ and Lanhui Guo ${ }^{1}$ \\ 1 School of Civil Engineering, Harbin Institute of Technology, Harbin 150090, China; \\ smzhang@hit.edu.cn (S.Z.); guolanhui@hit.edu.cn (L.G.) \\ 2 Shaanxi Key Laboratory of Safety and Durability of Concrete Structures, Xijing University, \\ Xi'an 710123, China \\ * Correspondence: gaoshan@hit.edu.cn
}

check for updates

Citation: Gao, S.; Zhang, S.; Guo, L. Application of Coal Gangue as a Coarse Aggregate in Green Concrete Production: A Review. Materials 2021, 14, 6803. https://doi.org/10.3390/ ma14226803

Academic Editor: Alessandro P. Fantilli

Received: 11 October 2021 Accepted: 8 November 2021 Published: 11 November 2021

Publisher's Note: MDPI stays neutral with regard to jurisdictional claims in published maps and institutional affiliations.

Copyright: (c) 2021 by the authors. Licensee MDPI, Basel, Switzerland. This article is an open access article distributed under the terms and conditions of the Creative Commons Attribution (CC BY) license (https:/ / creativecommons.org/licenses/by/ $4.0 /)$.

\begin{abstract}
Among the techniques for converting stacked coal gangue to reusable material, one of the most effective ways is to use coal gangue as a coarse aggregate in green concrete productions. The physical and chemical properties of rock and spontaneous-combustion coal gangue are generally suitable for being used as a coarse aggregate in green concrete. Coal gangue concrete is not recommended to be used in subsurface structures, as its water absorption law would be changed under a large replacement ratio. The mechanical performance of coal gangue concrete is degraded by raising the replacement ratio. Over-low and -high concrete grades are not suggested to be used as coal gangue aggregate, unless extra admixtures or specific methods are used. The influence of coal gangue on the durability of coal gangue concrete is remarkable, resulting from the porous structure of coal gangue that provides more transmission channels for air and liquid in concrete, but is beneficial for thermal insulation. The usage of coal gangue in structural concrete members is still limited. The mechanical behavior of some structural members using coal gangue concrete has been reported. Among them, concrete filled steel tubes are a preferable configuration for using coal gangue concrete, regarding both the mechanical and durability performance.
\end{abstract}

Keywords: coal gangue; green concrete; coarse aggregate; structural member; eco-friendly production

\section{Introduction}

Even though many kinds of new energy and renewable fuels have been explored nowadays, coal is still the main energy for many countries in the world, especially for countries in Asia Pacific region, such as China, Indonesia, and Vietnam. In fact, the increase of global coal production in 2019 resulted from the significant production increases of China and Vietnam, while that of other regions in the world declined, as shown in Figure 1 [1]. Coal still accounts for more than $70 \%$ of energy expenditure in China [2], while the world coal expenditure fell to its lowest level in 16 years, as a result of being displaced by natural gas and renewables.

Along with the excavation and washing of coal in the production process, large amounts of rock-like coal gangue (CG) accompanying the carboniferous beds are discharged as industrial residues, accounting for around $10-20 \%$ of the coal production [2-4]. In the largest coal production country, namely China, more than 700 million tons of coal gangue was expected in 2020, with the annual rate of 300-350 million tons [4,5], not to mention that almost 5 billion tons of that have been accumulated in China $[4,6]$ and the number for Europe is 175 million tons [2]. 


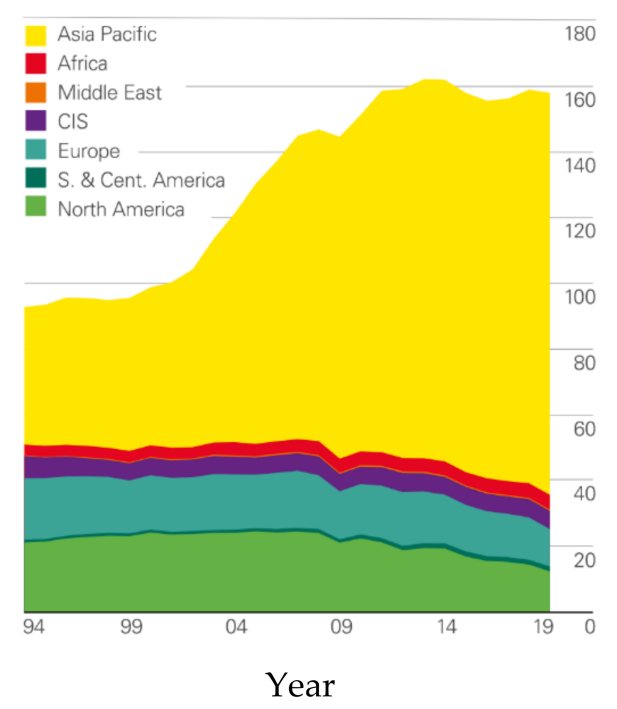

Exajoules

Figure 1. Coal consumption by region [1].

Even though the storage location of coal gangue is normally far away from downtown areas, the considerable stockpile of coal gangue still threatens human society, besides the natural ecosystem. Firstly, from the point of geotechnical engineering, rock-like coal gangue has to be stored in dumps, which obviously occupy enormous land resources that can be used for farming and construction. Furthermore, normal disordered gangue stacking tends to result in debris flow $[2,4,5]$. Secondly, it is well-known that the composition of coal gangue changes along with storage time and environment [7]. In other words, even though the major chemical compositions of gangue are $\mathrm{SiO}_{2}$ and $\mathrm{Al}_{2} \mathrm{O}_{3}$ in the form of quartz and feldspar [3], certain traces of various heavy metal elements, including $\mathrm{Pb}^{2+}$, $\mathrm{Zn}^{2+}$, and $\mathrm{Cu}^{2+}$, are still contained in coal gangue. After long-term weathering and soaking, the leaching of heavy metals would result in the contamination of soil, groundwater, and surface water, further harming the surrounding ecosystem and human health through bioaccumulation $[2,4,6,7]$. Last but not least, stocked coal gangue is also an emission resource of volatile organic chemical gas. The heat continuously accumulating inside the stocked coal gangue leads to the spontaneous combustion of coal gangue in the form of fire, even blast disasters, due to the existence of unburned coal, pyrite, and oxygen, releasing a large amount of harmful gases, including $\mathrm{SO}_{2}, \mathrm{NO}_{x}$, and $\mathrm{CO}$, into the atmosphere. It is a pity that this air pollution from coal gangue is hard to control $[2,4]$.

The gangue utilization rate of the main developed regions, such as US and Europe, is more than $90 \%$. In contrast, that value in the largest coal gangue production country, namely China, is only about $60-70 \%$, while the coal gangue utilization of China through combustion and calcination normally results in secondary pollution $[4,6]$. How to deal with the accumulation of coal gangue and improve its utilization rate has become one of the most crucial issues related to the sustainable development of the coal industry.

\section{Utilization of Coal Gangue}

For years, researchers have been working on the effective utilization of the enormous stocked coal gangue. In China, more than a half of discharged coal gangue is used for land reclamation - one third of that is used for power generation and the rest is used for producing building materials [2,4].

However, the main compositions of natural rock coal gangue are inactive $\mathrm{SiO}_{2}$ and $\mathrm{Al}_{2} \mathrm{O}_{3}$, whose cementitious ability is rather weak. Calcination or spontaneous combustion are necessary to add $\mathrm{CaO}$ to coal gangue. For now, the percentage of calcined gangue combination with Portland cement is still low, normally less than $15 \%[3,6]$. In contrast, as additive and fine aggregates, calcined gangue could also be used to prepare cementitious material, and is a promising replacement for fly ash and slag [8,9]. Meanwhile, coal gangue 
can be crashed and directly used as a lightweight aggregate, with a good internal curing capacity, but a high demand for water for mixing $[6,10,11]$.

Besides power generation, the current utilization methods of coal gangue, including land reclamation and producing cementitious materials, tend to cause secondary environmental contamination and extra energy consumption, as the calcination and superfine grinding of coal gangue seem inevitable. In contrast, the utilization of coal gangue as a coarse aggregate has a relatively low energy consumption and environmental impact. However, currently, most of the studies on the utilization of coal gangue focus on producing cementitious materials and additives. The limited studies on the utilization of coal gangue as a coarse aggregate only consider the mechanical and durability performance of the concrete material. The structural application of coal gangue coarse aggregate concrete, such as in beams, columns, and walls, is rather little and is not deep enough, which also includes design methods for structural members with coal gangue concrete.

Hereafter, this paper introduces the direct utilization of coal gangue for preparing structural concrete as a replacement of coarse aggregates, aiming at sustainable, comprehensive, and efficient cleaner production. Through this review, it is hoped that more structural applications of coal gangue coarse aggregate concrete would be proposed and studied experimentally and theoretically.

\section{Methods}

The references for the review were searched for in December 2020 in Scopus and the China National Knowledge Internet database, with the consideration of the following factors [4]:

(1) The presence of terms "coal gangue" and "coarse aggregate" in the documents;

(2) The considered period: 1990-2020;

(3) The publication form of paper: "Article" or "Review";

(4) Searching area: "Engineering" and "Material".

It should be mentioned that as the focus of this review is the coal gangue utilization of coarse aggregates, most of the references regarding gangue utilization in producing cementitious materials are not mentioned. In fact, studies on gangue utilization of coarse aggregates for the preparation of concrete mainly performed by Chinese researchers are much less than that for the production of cementitious materials, as China remains the largest production country in the world and the coal consumption in other countries and regions has been dropping for decades. Referring to the application of coal gangue in concrete structural members, the relevant studies have only been performed by Chinese researchers for the same reason. The main work of this review is summarized in Figure 2.

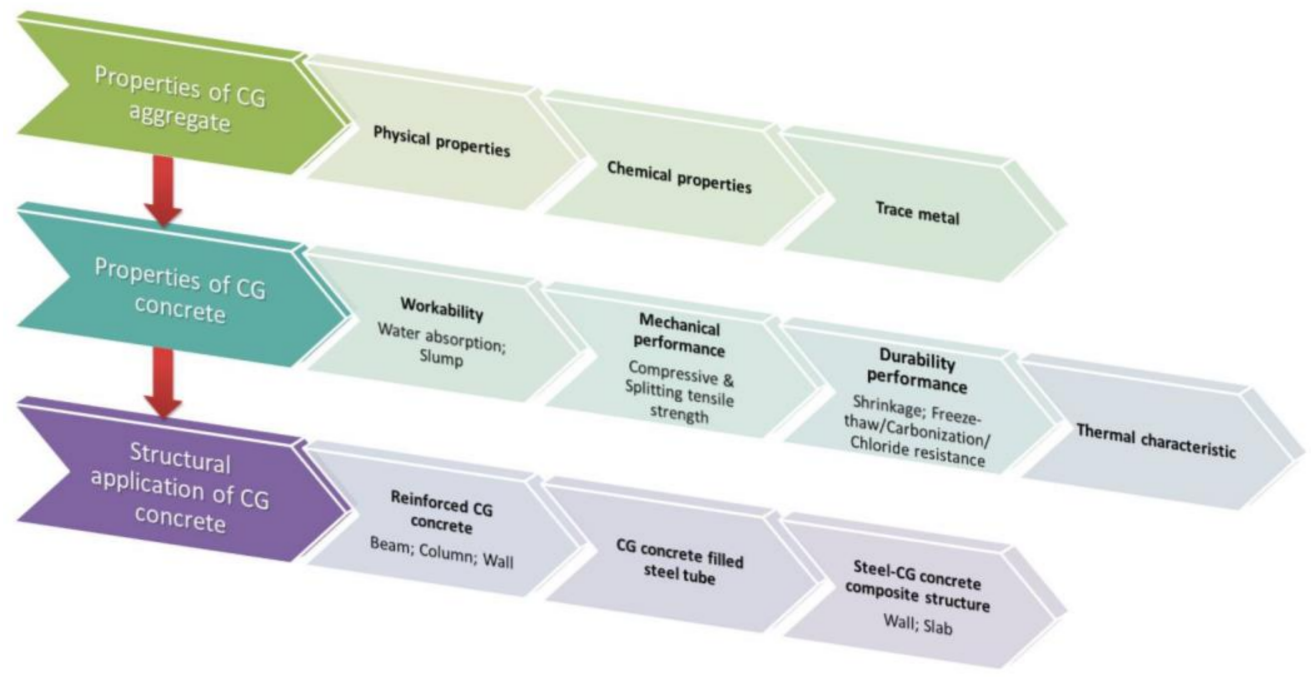

Figure 2. Flowchart of the review. 


\section{Properties of Coal Gangue Aggregate \\ 4.1. Physical Properties}

Natural coal gangue (namely rock coal gangue) is a rock-like mining waste that normally appears from gray to black. The color changes to whitish gray and even red after spontaneous combustion or after being calcinated, according to its iron oxide content and weathering degree [2]. According to Chinese standard JGJ-52-2006, the physical properties of rock coal gangue (RCG) and spontaneous-combustion coal gangue (SCG) vary from different origins in China, as summarized in Table 1 [12-24].

Table 1. Physical properties of coal gangue aggregate from different origins in China.

\begin{tabular}{|c|c|c|c|c|c|c|c|c|}
\hline Type & $\begin{array}{l}\text { Region of } \\
\text { China }\end{array}$ & Province & $\begin{array}{c}\text { Apparent Density } \\
\left(\mathrm{kg} / \mathrm{m}^{3}\right)\end{array}$ & $\begin{array}{c}\text { Bulk Density } \\
\left(\mathrm{kg} / \mathrm{m}^{3}\right)\end{array}$ & Water Absorption & $\underset{(\%)}{\text { Crushing Value }}$ & $\begin{array}{c}\text { Void Ratio } \\
(\%)\end{array}$ & Ref. \\
\hline \multirow{5}{*}{ SCG } & \multirow{4}{*}{ Northeast } & Heilongjiang & 2588 & 1289 & 3.8 & 18.9 & 50.2 & [13] \\
\hline & & Liaoning & 2497 & & 9.80 & 25.2 & & [12] \\
\hline & & Liaoning & 2630 & 1550 & 8.5 & 16.6 & 22.0 & [14] \\
\hline & & Liaoning & 2276 & 1220 & 7.55 & 21.2 & 52.8 & [15] \\
\hline & South & $\begin{array}{l}\text { Anhui } \\
\text { Jiangsu }\end{array}$ & $\begin{array}{l}2630 \\
2624\end{array}$ & $\begin{array}{c}976 \\
1430\end{array}$ & $\begin{array}{c}9.2 \\
4.88\end{array}$ & $\begin{array}{l}16.6 \\
24.4\end{array}$ & 57.9 & $\begin{array}{l}{[16]} \\
{[17]}\end{array}$ \\
\hline \multirow{8}{*}{ RCG } & Northeast & Liaoning & 2653 & 1489 & 3.15 & 9.9 & 49.5 & [15] \\
\hline & \multirow{5}{*}{ North } & Shanxi & 2083 & 1130 & 4.7 & 18.7 & - & [18] \\
\hline & & Shanxi & 2689 & 1201 & 11.4 & 18.1 & . & [19] \\
\hline & & Beijing & 2640 & - & 1.8 & 22.6 & - & [20] \\
\hline & & Henan & 2510 & 1320 & 1.7 & 19.1 & 47.5 & [21] \\
\hline & & Henan & 2540 & 1264 & 3.9 & 17.9 & 51.5 & [22] \\
\hline & Northwest & Shaanxi & 2090 & - & 4.92 & 19.0 & - & [23] \\
\hline & South & $\begin{array}{l}\text { Jiangsu } \\
\text { Jiangsu }\end{array}$ & $\begin{array}{l}2712 \\
2620\end{array}$ & $\begin{array}{c}- \\
1612\end{array}$ & $\begin{array}{l}1.7 \\
3.9\end{array}$ & $\begin{array}{l}16.8 \\
18.6\end{array}$ & - & [24] \\
\hline
\end{tabular}

The apparent density of gangue is approximately $2600 \mathrm{~kg} / \mathrm{m}^{3}$, which is similar to natural stone, while its bulk density is approximately $1200 \mathrm{~kg} / \mathrm{m}^{3}$, which belongs to lightweight aggregate. The water absorption and crushing value of gangue (approximately $5 \%$ and $20 \%$ respectively) are relatively larger than those of natural stone (approximately $2 \%$ and $15 \%$, respectively) due to its higher carbon content. Although calcination would reduce the carbon content in RCG, its water absorption and crushing value would also be further enlarged. Even though some crashing values of CG in Table 1 are close to or even smaller than the conventional crashing values of natural rock, these values are still larger than those of the natural rock collected from the local in the corresponding references.

As the replacement of natural coarse aggregate, both RCG and SCG seem to be a little fragile to be used in concrete, which may likely result in the fracture in coal gangue aggregate itself, besides the fracture in the interfacial transition zone (ITZ).

\subsection{Chemical Properties}

According to its chemical properties, coal gangue could be categorized into four types, namely claystone gangue $\left(\mathrm{SiO}_{2}: 40-70 \%\right.$ and $\left.\mathrm{Al}_{2} \mathrm{O}_{3}: 15-30 \%\right)$, sandstone gangue $\left(\mathrm{SiO}_{2}>70 \%\right)$, aluminous stone gangue $\left(\mathrm{Al}_{2} \mathrm{O}_{3}>40 \%\right)$, and calcareous stone gangue $(\mathrm{CaO}>30 \%)$ [25] Table 2 lists the mineralogical composition of coal gangue in various countries [26]. Typical coal gangue contains $50-70 \%$ clay minerals, $20-30 \%$ quartz, and $10-20 \%$ other minerals and carbon impurity. Compared with Europe and South America, the content of kaolinite in the coal gangue of China and USSR is richer, showing more potential for reuse, as kaolinite is apt to be activated. Instead, the content of illite in the coal gangue of Europe is much richer than that in USSR and China. 
Table 2. Mineralogical composition of coal gangue in various countries/\% [26].

\begin{tabular}{ccccccc}
\hline Minerals & Czechoslovakia & Germany & Spain & Britain & USSR & China \\
\hline Illite & $10-45$ & $41-66$ & $20-60$ & $10-31$ & $5-30$ & $10-30$ \\
Kaolinite & $24-45$ & $4-25$ & $3-30$ & $10-40$ & $1-60$ & $-6-67$ \\
Chlorite & $0-15$ & $1-3$ & $0-7$ & $5-57$ & $15-25$ & -11 \\
Quartz & $10-50$ & $13-27$ & - & $2-10$ & $0.2-8$ & $15-35$ \\
Iron ore & $0-25$ & $0.5-5$ & $4-30$ & $5-25$ & $8-40$ & $5-25$ \\
Organic matters & $0-25$ & $5-10$ & &
\end{tabular}

In general, as coal gangue is actually a transition substance between rock and coal, its chemical composition is similar to that of natural coarse aggregate, which also confirms the feasibility of being a coarse aggregate in concrete production.

As listed in Table 3, the content of $\mathrm{SiO}_{2}$ is always maximum among the chemical composition in coal gangue, regardless of the origins, while the content of $\mathrm{Al}_{2} \mathrm{O}_{3}$ is normally half that of $\mathrm{SiO}_{2}$. The major chemical compositions of coal gangue, namely $\mathrm{SiO}_{2}$ and $\mathrm{Al}_{2} \mathrm{O}_{3}$, tend to increase after spontaneous-combustion or being calcinated, but still vary from different origins. As the content of $\left(\mathrm{SiO}_{2}+\mathrm{Al}_{2} \mathrm{O}_{3}+\mathrm{Fe}_{2} \mathrm{O}_{3}\right)$ in gangue normally accounts for more than $70 \%$, coal gangue could be treated as a pozzolanic material, regardless of its origin [2].

Table 3. Chemical composition of CG (mass fraction) /\%.

\begin{tabular}{|c|c|c|c|c|c|c|c|c|c|c|c|c|c|c|}
\hline Type & Region & Province & $\mathrm{SiO}_{2}$ & $\mathrm{Al}_{2} \mathrm{O}_{3}$ & $\mathrm{Fe}_{2} \mathrm{O}_{3}$ & $\mathrm{CaO}$ & $\mathrm{MgO}$ & $\mathrm{Na}_{2} \mathrm{O}$ & $\mathrm{K}_{2} \mathrm{O}$ & $\mathrm{TiO}_{2}$ & $\mathrm{P}_{2} \mathrm{O}_{5}$ & $\mathrm{SO}_{3}$ & Loss & Ref. \\
\hline \multirow{15}{*}{ RCG } & \multirow{3}{*}{$\begin{array}{l}\text { Northeast } \\
\text { of China }\end{array}$} & Heilongjiang & 61.0 & 23.6 & 6.70 & 1.18 & 0.52 & - & - & - & - & - & 2.50 & [11] \\
\hline & & Heilongjiang & 34.1 & 26.0 & 0.49 & 0.67 & 0.61 & - & 0.16 & - & - & 0.28 & 32.8 & [27] \\
\hline & & Liaoning & 50.3 & 26.3 & 6.11 & 7.74 & 2.00 & 1.10 & 3.28 & 1.13 & 0.15 & 0.93 & - & [15] \\
\hline & \multirow{5}{*}{$\begin{array}{l}\text { North } \\
\text { of China }\end{array}$} & Beijing & 49.9 & 24.4 & 6.42 & 0.82 & 1.59 & 1.46 & 2.06 & 0.88 & - & 0.12 & 11.8 & [3] \\
\hline & & Shandong & 48.8 & 19.0 & 4.47 & 2.03 & 2.29 & 1.43 & 0.19 & - & - & - & 16.8 & [3] \\
\hline & & Henan & 59.9 & 20.7 & 6.70 & 2.00 & 1.80 & 0.65 & 2.40 & - & - & 1.53 & - & [7] \\
\hline & & Shanxi & 35.1 & 16.8 & 27.3 & 3.82 & 1.60 & - & - & - & - & 3.00 & 0.83 & [19] \\
\hline & & Hebei & 48.3 & 23.1 & 4.30 & 4.10 & 1.70 & 0.10 & 1.50 & 0.80 & 0.10 & 1.00 & 14.7 & [28] \\
\hline & $\begin{array}{l}\text { Northwest } \\
\text { of China }\end{array}$ & Shaanxi & 49.5 & 33.3 & 7.60 & 6.09 & 0.97 & 0.52 & 0.94 & 0.83 & - & - & - & [23] \\
\hline & \multirow{2}{*}{$\begin{array}{l}\text { South } \\
\text { of China }\end{array}$} & Jiangsu & 55.5 & 18.2 & 5.42 & 3.38 & 1.23 & 0.64 & 1.67 & - & - & 0.64 & 13.3 & [3] \\
\hline & & Jiangsu & 59.8 & 29.4 & 1.44 & 0.68 & 0.51 & 0.08 & 1.76 & - & - & - & - & [8] \\
\hline & Poland & - & 58.9 & 20.5 & 6.63 & 0.35 & 1.93 & 0.54 & 3.19 & 1.05 & 0.06 & 0.17 & 5.50 & [5] \\
\hline & \multirow{3}{*}{ Italy } & No. 1 & 43.7 & 21.4 & 5.57 & 0.89 & 0.77 & 0.11 & 0.16 & 1.05 & 0.16 & 1.02 & 25.2 & \multirow{3}{*}{ [29] } \\
\hline & & No. 2 & 46.8 & 17.2 & 7.67 & 7.60 & 0.99 & 0.15 & 2.40 & 0.78 & 0.16 & 0.34 & 15.8 & \\
\hline & & No. 3 & 57.2 & 18.7 & 6.25 & 1.86 & 1.42 & 0.46 & 3.59 & 0.95 & 0.14 & 0.08 & 9.28 & \\
\hline \multirow{6}{*}{ SCG } & $\begin{array}{l}\text { Northeast } \\
\text { of China }\end{array}$ & Liaoning & 55.6 & 21.0 & 6.57 & 3.65 & 2.50 & 1.90 & 4.10 & 0.84 & 0.24 & 0.82 & - & [15] \\
\hline & $\begin{array}{c}\text { North } \\
\text { of China }\end{array}$ & Shanxi & 56.6 & 36.8 & 1.95 & 0.62 & 0.22 & 0.42 & - & 2.10 & - & - & - & [9] \\
\hline & $\begin{array}{l}\text { Northwest } \\
\text { of China }\end{array}$ & Shaanxi & 55.2 & 31.1 & 2.94 & 1.31 & 0.75 & 0.12 & 1.13 & 1.12 & 0.07 & - & 5.94 & [30] \\
\hline & \multirow{3}{*}{ Italy } & No. 1 & 56.4 & 26.3 & 6.42 & 1.06 & 1.07 & 4.02 & 0.17 & 1.21 & 0.20 & 0.65 & 2.38 & \multirow{3}{*}{ [29] } \\
\hline & & No. 2 & 52.3 & 19.5 & 8.35 & 8.41 & 1.21 & 2.65 & 0.20 & 0.85 & 0.17 & 0.49 & 5.61 & \\
\hline & & No. 3 & 61.9 & 20.2 & 6.77 & 2.00 & 1.57 & 3.78 & 0.53 & 1.01 & 0.15 & 0.11 & 1.81 & \\
\hline
\end{tabular}

\subsection{Trace Metal}

The heavy metal content of coal gangue and the permissible values in soils and surface lands are listed in Table 4. Similar to the chemical composition, the heavy metals in gangue also vary according to the origins. The $\mathrm{Cr}$ content of coal gangue in Italy is much higher 
than that in China and Poland, while the As content of coal gangue in China is a little higher than the permissible value. Besides this, the heavy metal content of gangue is much lower than the permission level of the Polish Regulation of the Ministry of Environment of 9 September 2002 for soil quality standards and earth quality standards. In addition, the short-term leachability of the heavy metals is relatively weak [5]. In this case, in terms of environmental protection, coal gangue could also be used as a coarse aggregate in green concrete production. However, more data regarding the heavy metal content in coal gangue should be collected from testing in order to propose a more accurate requirement regarding the heavy metal content of discharged coal gangue. In addition, the content of heavy metal in discharged coal gangue should be tested before being used in a concrete mixture so as to make sure that its utilization would not pose an environmental, health, and safety concern.

Table 4. Content of heavy metals in coal gangue $/ \mathrm{mg} \mathrm{kg}^{-1}$.

\begin{tabular}{|c|c|c|c|c|c|c|c|c|c|c|c|c|c|c|c|}
\hline Type & Region & Province & As & $\mathrm{Ba}$ & $\mathrm{Cd}$ & Co & $\mathrm{Cr}$ & $\mathrm{Cu}$ & $\mathrm{Hg}$ & Mo & $\mathrm{Ni}$ & $\mathrm{Pb}$ & Sn & $\mathrm{Zn}$ & Ref. \\
\hline $\mathrm{RCG}$ & China & Jiangsu & 27.3 & - & 0.58 & - & 42.3 & 24.3 & 0.24 & - & 20.5 & 4.32 & - & 39.5 & [31] \\
\hline \multirow{3}{*}{ SCG } & \multirow{3}{*}{ Italy } & No. 1 & - & - & - & - & 190 & - & - & - & 56 & 11 & - & 27 & \multirow{3}{*}{ [29] } \\
\hline & & No. 2 & - & - & - & - & 228 & - & - & - & 43 & 5 & - & 46 & \\
\hline & & No. 3 & - & - & - & - & 308 & - & - & - & 57 & 10 & - & 37 & \\
\hline RCG & Poland & - & $<2$ & 84.5 & 2.9 & 14.6 & 61.9 & 48.3 & 0.04 & $<2$ & 41.2 & 20 & 3 & 89.5 & [5] \\
\hline \multicolumn{3}{|c|}{ Permission content in Poland } & 20 & 200 & 4 & 20 & 150 & 150 & 2 & 10 & 100 & 100 & 20 & 300 & [5] \\
\hline
\end{tabular}

\section{Properties of Coal Gangue Concrete}

Even though using crashed and sieved coal gangue as a coarse aggregate is the most convenient and energy-saving method to utilize coal gangue, the feasibility of this method still depends on the properties of coal gangue. The performance of coal gangue concrete needs to meet the standard for preparing the concrete in construction. Calcination is beneficial for improving the interfacial bond between coal gangue and cement mortar.

\subsection{Workability}

\subsubsection{Water Absorption}

It is foreseeable that the water absorption of coal gangue concrete would be increased by raising the coal gangue replacement ratio, as its water absorption is higher than that of natural gravel. Figure $3 \mathrm{a}$ shows the permeability coefficient of the concrete under $25 \%$ and $30 \%$ replacement ratios. The increase of the pore phase conductivity by increasing the coal gangue replacement is supposed to result in an increase of the permeability coefficient [31]. Furthermore, the water absorption law tested according to ASTM C1585 was remarkably changed, as shown in Figure 3b. The inflection point for the water absorption speed in the curves became more and more obvious with the increase of the replacement ratio. Under a large replacement ratio, coal gangue aggregate in concrete became almost saturated in a short time, and then the unsaturated mortar and natural aggregates continued to absorb water, with a water absorption speed much lower than that of the coal gangue. Comparing the results in [31,32], as shown in Figure 3b, it seems a coal gangue replacement ratio lower than $30 \%$ would not significantly affect the water absorption of the concrete. In general, coal gangue concrete is not recommended for use in subsurface structures; besides, it is obvious that a large water absorption would reduce the strength of the coal gangue concrete. 


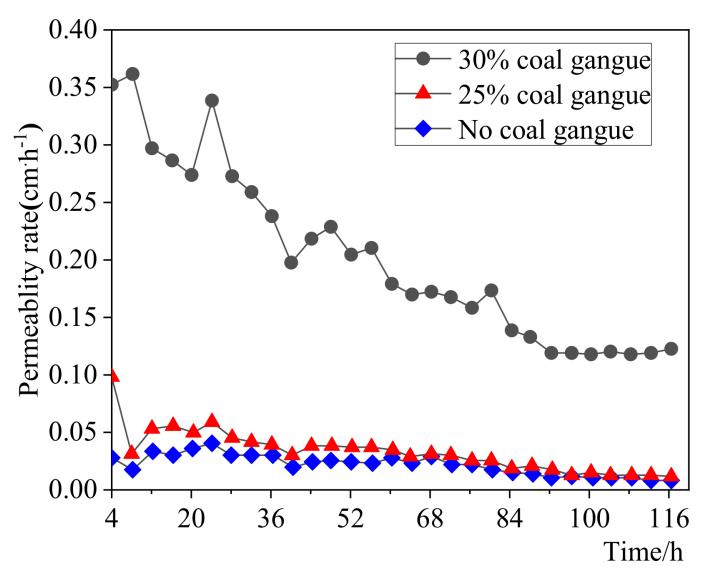

(a)

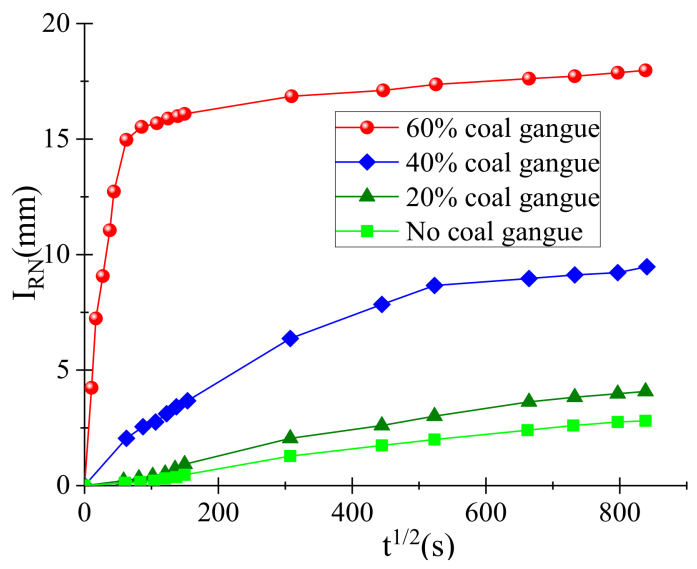

(b)

Figure 3. Effect of rock coal gangue replacement on the water absorption of coal gangue concrete. (a) Permeability coefficient [31]; (b) Absorption depth [32].

\subsubsection{Slump}

As coal gangue (CG) shows a larger water absorption capacity than natural aggregate, the workability of coal gangue concrete would obviously be decreased by raising the CG replacement ratio according to Chinese standard GB 50164-2011, as shown in Figure 4. Under a 50\% CG replacement ratio, the slump of the coal gangue concrete would be reduced by about $10 \%$, while the number would be $20 \%$ under $100 \%$ CG replacement ratio. As the properties of CG vary from the origin, the difference between RCG and SCG shown in Figure 5 is subtle $[33,34]$. To enhance its workability, adding fly ash and superplasticizer in coal gangue concrete are both effective and simple methods [35,36]. Additional water consumption for coal gangue could also be a choice to enhance the workability, but would result in a strength reduction of coal gangue concrete resulting from the extra water [37]. It is surprising from Figure 4 that the pre-soaking method is not as effective as it is supposed to be, which may be also due to the properties of coal gangue varying from the origin.

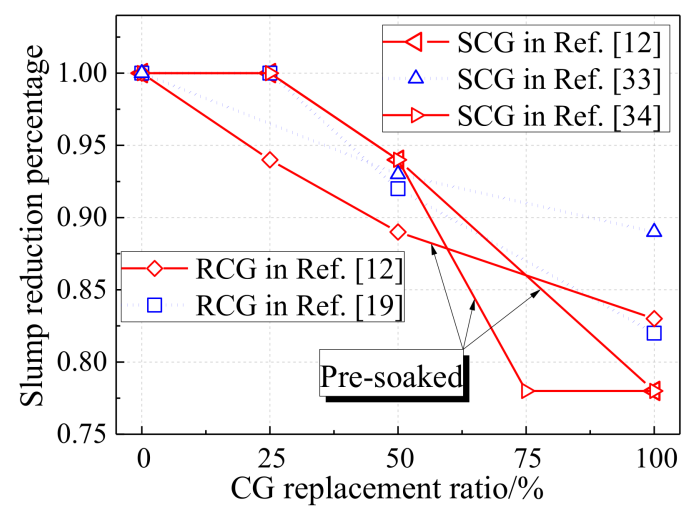

Figure 4. Effect of coal gangue replacement on the slump of coal gangue concrete. 


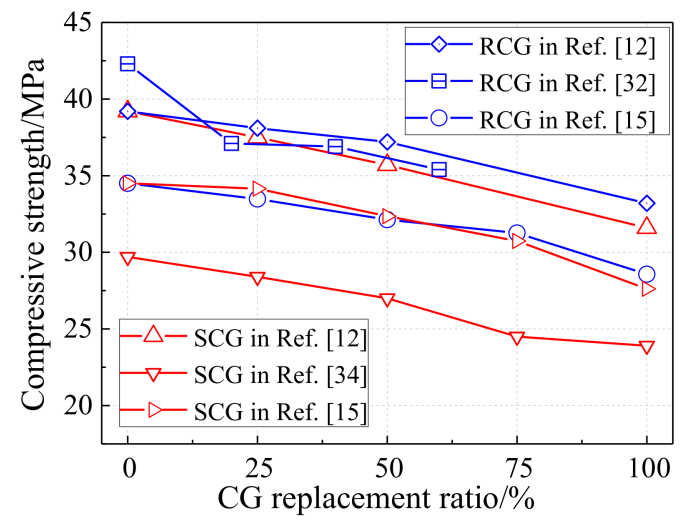

(a)

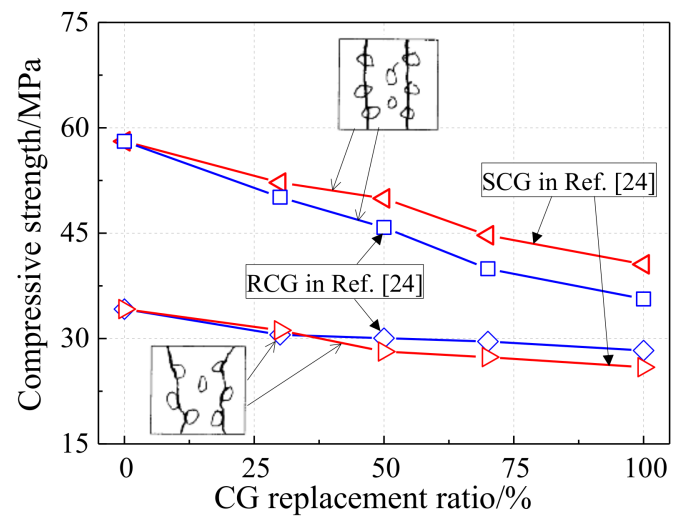

(b)

Figure 5. Effect of coal gangue replacement on the compressive strength of coal gangue concrete. (a) Compressive strength; (b) Failure pattern.

\subsection{Mechanical Performance \\ 5.2.1. Compressive Strength}

It is assumed that the porous structure of CG results in a strength reduction of coal gangue concrete. As shown in Figure 5a, the compressive strength of coal gangue concrete tested according to Chinese standard GB 50010-2010 decreases approximately linearly with the rise of the replacement ratio, regardless of concrete strength and the type of coal gangue. Under $100 \%$ CG replacement ratio, the compressive strength of coal gangue concrete decreased by around 15-20\% [12,15,32,34]. Figure $5 \mathrm{~b}$ indicates that the failure pattern of coal gangue concrete is different according to the concrete grade [24]. Under a low concrete grade, the failure of coal gangue concrete occurs in the mortar, where the coal gangue shows little effect. In contrast, under a high concrete grade, the failure of coal gangue concrete happens in both the mortar and coal gangue aggregate. In this case, the types of coal gangue aggregate contribute to the compressive strength of coal gangue concrete. As mentioned above, calcinating CG would activate the cementitious composition in it and improve the strength of the mortar, but would degrade the strength of the coal gangue itself. In addition, an over-low concrete grade, for example lower than C20, is not suggested for use as a coal gangue aggregate, as the mortar is not enough to fully cover the coarse aggregate, which may lead to a significant reduction in the mechanical properties of coal gangue concrete [38].

Similar to ordinary concrete, adding steel fiber could reinforce the mechanical properties of coal gangue concrete. The compressive strength of coal gangue concrete with $2 \%$ steel fiber would be improved by $16.7 \%$ [39]. Furthermore, calcianting RCG [40] and presoaking SCG [17] would also achieve the same effect.

As presented in Figure 6, even though a general descending trend in the elastic modulus of coal gangue concrete was found when raising the CG replacement ratio, the comparsion between the RCG concrete and SCG concrete was contrary between [12] and [15]. In other words, the elastic modulus of RCG concrete was larger than that of the SCG concrete [12], whiet the former was smaller than the latter in [15], except for the $100 \%$ replacement ratio. Besides the discreetness of coal gangue properties, the presoaking method, which is supposed to effectvely improve the mechanical behaviors of SCG concrete, rather than those of RCG concrete, was used in [15]. 


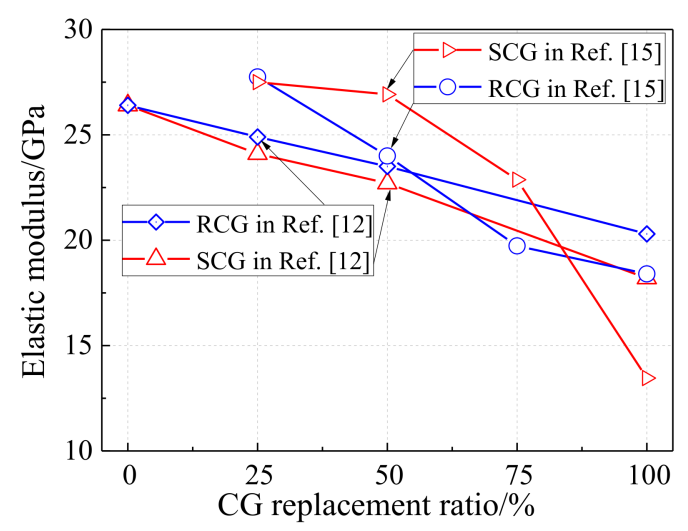

Figure 6. Effect of coal gangue replacement on the elastic modulus of coal gangue concrete.

Figure 7 presents the stress-strain relationship of the concrete with different contents of RCG and SCG [15]. It indicates that increasing both the RCG and SCG replacement ratios would increase the peak strain of the coal gangue concrete. The drop beyond the peak in the curves of RCG concrete was sharper than that of the SCG concrete, due to the porous structure of SCG. These phenomena imply that the ductility of SCG concrete is better than that of RCG concrete. Based on the tested stress-strain relationship of coal gangue concrete and the model in Chinese standard GB 50010-2010, a dimensionless model $\left(x=\varepsilon / \varepsilon_{\mathcal{C}}, y=\sigma / \sigma_{\mathcal{c}}\right)$ for both RCG and SCG concrete is proposed for the first time, as follows [15]. The proposed model should consider the aggregate replacement ratio and CG types. However, more data regarding the stress-strain relationship model of CG concrete are still needed to validate the model, as it was empirically obtained and the properties of CG vary according to the origin.

$$
y=\left\{\begin{array}{c}
a x+(3-2 a) x^{2}+(a-2) x^{3}, 0 \leq x \leq 1 \\
x /\left(b(x-1)^{2}+x\right), x>1
\end{array}\right.
$$

where $a$ is $(-0.0112 r+1.844)$ and $\left(7 \times 10 r^{-5}-0.0117 r^{2}+1.6866\right)$ for RCG and SCG, respectively, and $b$ is $(0.1052 r+1.824)$ and $(-0.0118 r+2.38)$ for RCG and SCG, respectively.

\subsubsection{Splitting Tensile Strength}

As shown in Figure 8, generally, the splitting tensile strength of coal gangue concrete decreases as the CG replacement ratio increases. However, due to the discreetness of thecoal gangue properties, a minimum value was observed in the results of RCG concrete in [15] under 50\% CG replacement ratio. By using CG as the coarse aggregate, more splitting tensile damage was found in the coarse aggregate, namely coal gangue, rather than in the bond between the coarse aggregate and the matrix.

\subsection{Durability Performance}

\subsubsection{Shrinkage}

The cracks resulting from shrinkage affect the durability of concrete, especially for concrete with CG whose water absorption characteristic is different to the natural coarse aggregate. Figure 9a shows the effect of concrete grade on the coal gangue concrete shrinkage tested according to the GB/T 50082-2009 standard and ASTM C157. It is obvious that higher-grade coal gangue concrete shows larger shrinkage. It is also interesting that the early shrinkage of coal gangue concrete is smaller than that of normal concrete, which results from the inner curing effect of coal gangue with a large water absorption [41]. As shown in Figure 9b, the increase of shrinkage due to the increase of curing temperature would be enlarged by raising the CG replacement ratio [42]. As expected, the concrete using an SCG aggregate and large replacement ratio showed large shrinkage, as shown in Figure 9c [12]. However, a totally opposite trend, where increasing the replacement ratio decreased the shrinkage of concrete was still observed, as seen in Figure 9d [43]. This 
finding may result from the larger volume of coal gangue used in the concrete mixture under the same mass replacement ratio of the coarse aggregate, which would reduce the shrinkage of the mortar matrix.

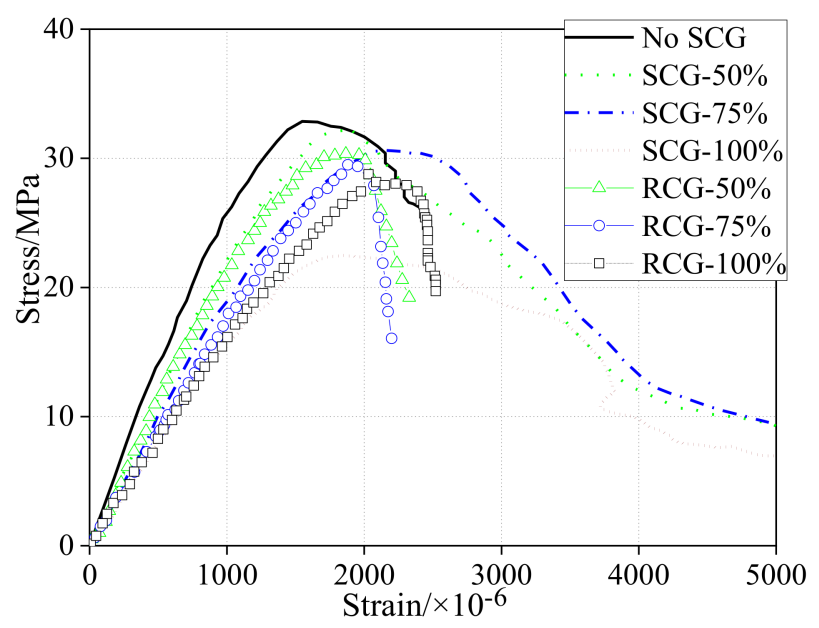

Figure 7. Stress-strain curves of the coal gangue concrete [15].

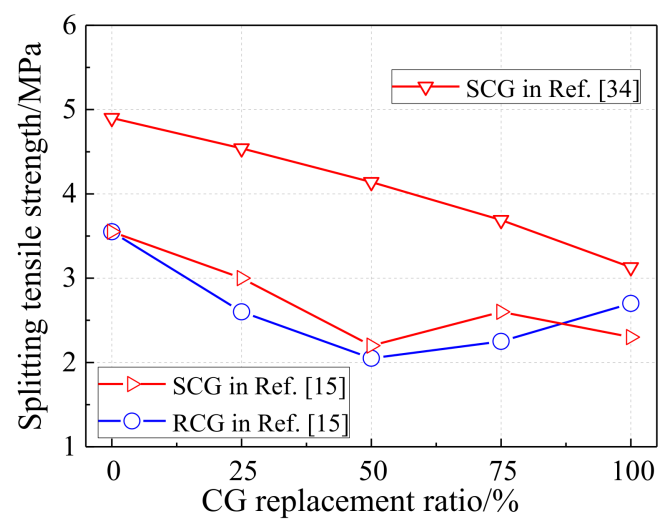

Figure 8. Effect of coal gangue replacement on splitting tensile strength of coal gangue concrete.

\subsubsection{Freeze-Thaw Resistance}

The failure of concrete under freezing-thawing cycles results from the frost-heave stress related to the capillary water absorption properties [44]. Due to the large frost-heave stress resulting from the porous structure of CG, the mechanical performance of coal gangue concrete was significantly affected by freezing-thawing cycles from the test complying with Chinese standard GB/T 50082-2009, which was enlarged by raising the CG replacement ratio [32,45]. The freezing - thawing mass loss of coal gangue concrete would also be enlarged by increasing the water-cement ratio [46].

Based on the tested results, a dimensionless model $\left(x=\varepsilon / \varepsilon_{c}, y=\sigma / \sigma_{c}\right)$ of the stress-strain relationship is proposed for coal gangue concrete after freezing-thawing cycles [23]. The model modified from the model in Chinese standard GB 50010-2010 considers the effects of the CG replacement ratio and the cycle number of freezing-thawing, rather than the CG type. Therefore, similar to the model proposed in [15], even though this model fit well with the test results, it was also empirically obtained, which means that more data are needed in order to validate it. 


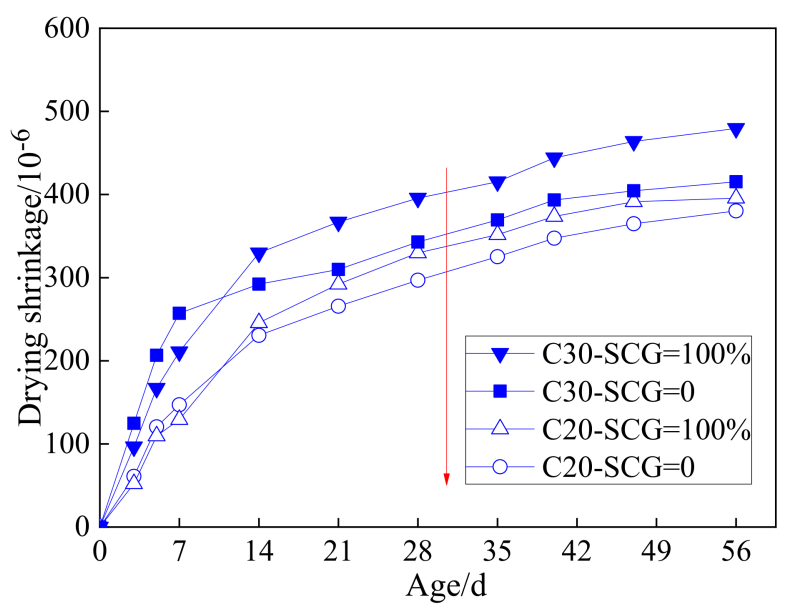

(a)

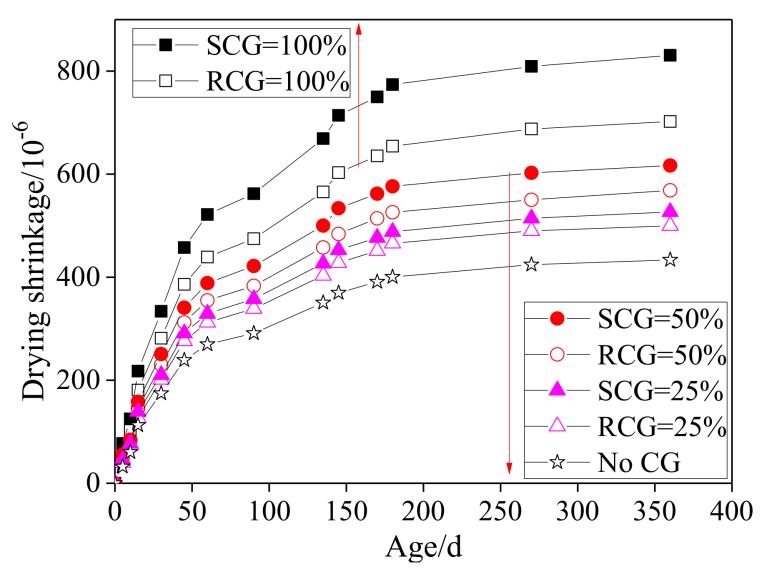

(c)

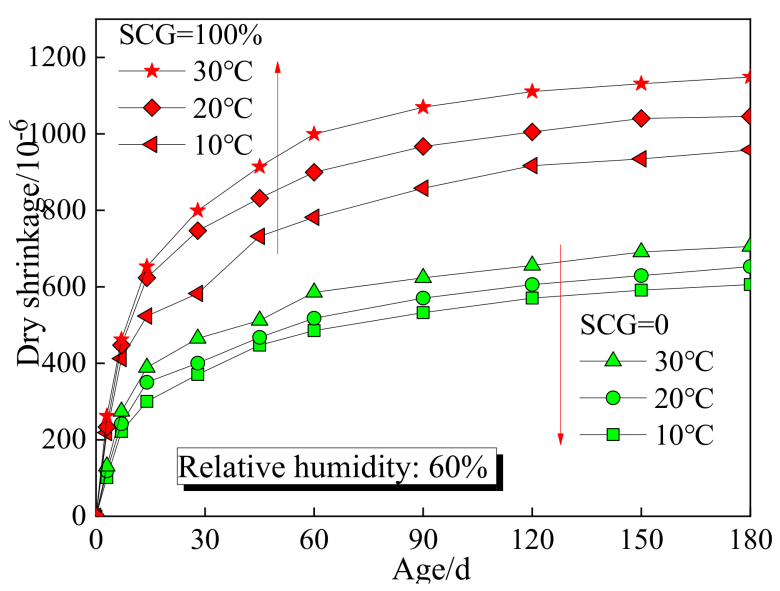

(b)

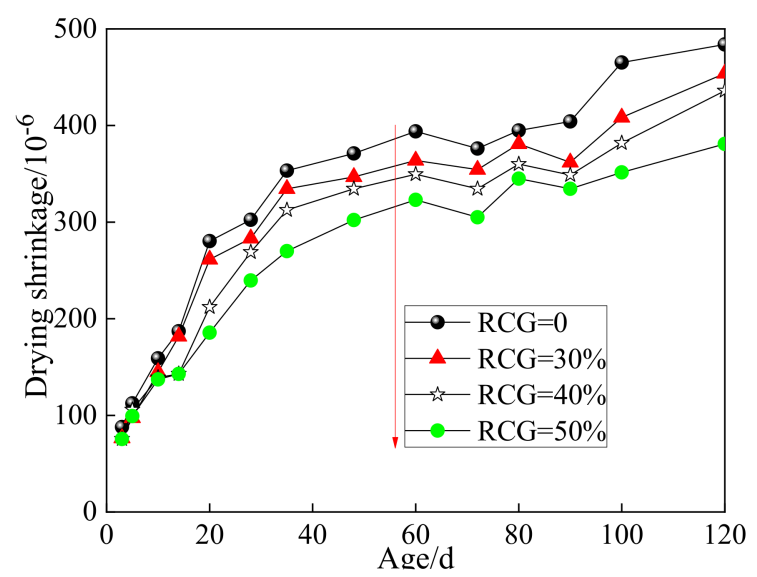

(d)

Figure 9. Effect of coal gangue replacement on the shrinkage of coal gangue concrete. (a) Concrete grade [41]; (b) Curing condition [42]; (c) Coal gangue type [12]; (d) Replacement ratio (RCG) [43].

$$
y=\left\{\begin{array}{c}
(1.92-\mu N) x+(1.08+\mu N) x^{2}-(0.08+\mu N) x^{3}, 0 \leq x<1 \\
x /\left((1.3+\eta N)(x-1)^{2}+x\right), x \geq 1
\end{array}\right.
$$

where $\mu$ is $\left(0.0025 e^{0.0552 r C G}\right), \eta$ is $\left(0.0035+0.0011 r_{C G}\right), N$ is the cycle number of freezing-thawing, and $r_{\mathrm{CG}}$ is the CG replacement ratio.

The admixture of fly ash and silica fume [47], organic anti-freezing agent [48], and polypropylene fiber [49] are added into the coal gangue concrete to enhance its freeze-thawing resistance. Up to $1 \%$ of organic anti-freezing agent, namely ethylene glycol, could improve the freeze-thawing resistance of coal gangue concrete by $10-30 \%$, which is believed to be one of the most effective methods.

\subsubsection{Carbonization Resistance}

The transmission of $\mathrm{CO}_{2}$ in concrete is mainly affected by the porosity ratio and connected channels. The coal gangue aggregate generally has more pores than natural gravel. The air containing $\mathrm{CO}_{2}$ enters into the concrete more easily, resulting in a poor durability of the concrete [50]. Therefore, it is obvious that increasing the coal gangue replacement ratio would reduce the carbonization resistance of coal gangue concrete (seen in Figure 10, showing the results from the test complying with Chinese standard GB/T 50082-2009) [51]. 


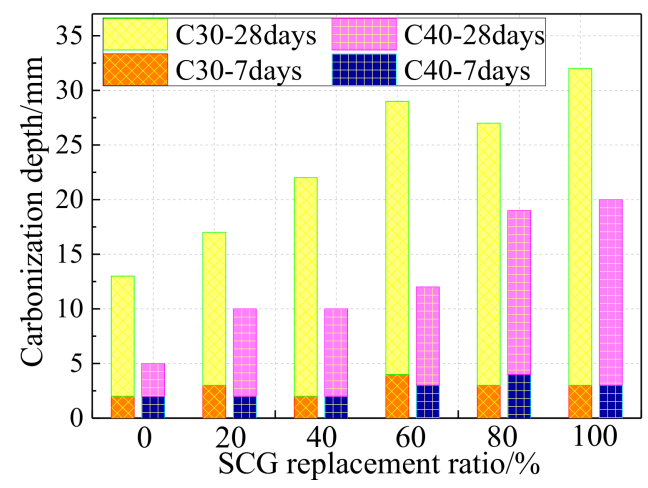

Figure 10. Carbonization depth-SCG replacement ratio relationship.

Figure 10 also implies a finding that the carbonization depth of SCG concrete is negatively related to its strength, which was also found in other relavent tests [52,53]. A formula describing the relationship between carbonization depth $d_{\mathrm{c}}$ and strength $f_{\mathrm{CG}}$ of SCG concrete after 28 days of curing is proposed as follows [53]. This empirical model is not only related to one parameter, namely CG strength, but is also valid in the scope of concrete strength.

$$
d_{c}=-0.31 f_{C G}+29.6,\left(18.7 \leq f_{c} \leq 51.2\right)
$$

Compared with RCG, the concrete using $700{ }^{\circ} \mathrm{C}$-calcinated coal gangue has a better carbonization resistance than that of RCG concrete. C-S-H hydrogel, which is produced by the second hydration reaction among the $\mathrm{SiO}_{2}, \mathrm{Al}_{2} \mathrm{O}_{3}$, and cement hydration product $\mathrm{Ca}(\mathrm{OH})_{2}$ produced after the calcination of the gangue aggregate, compacts the pores and reduces the $\mathrm{CO}_{2}$ transmission channel in concrete. A formula for predicting the carbonization depth of RCG concrete regarding age $(t)$, water-cement ratio $\left(m_{\mathrm{w}} / m_{\mathrm{c}}\right)$, and coal gangue replacement ratio $\left(r_{\mathrm{CG}}\right)$ is proposed [54]. Compared with Equation (3) from [53], this empirical formula considers the effects of three different parameters, instead of just the concrete strength. However, as mentioned by the authors themselves, this formula is only suitable for RCG, rather than SCG.

$$
d_{c}=0.098 \sqrt{t}+50.66 m_{w} / m_{c}+2.015 r_{C G}-17
$$

\subsubsection{Chloride Resistance}

More capillary pores in SCG are the main reason for the poor chloride resistance of coal gangue concrete. Therefore, in the coal gangue concrete with a low water-cement ratio, the gel pores and capillary pores are filled with hydrated gel, increasing the compactness of the concrete larger, decreasing the electric flux, and enhancing the chloride ion penetration resistance [55-57].

To improve the chloride resistance of coal gangue concrete, calcination [24], adding steel fiber [39], and adding the mineral admixture and superplasticizer [58] are effective ways that could reduce the micro cracks of mortar matrix and change the ion permeation path. As shown in Figure 11, where the results are from the test complying with ASTM C 1202-05, adding fly ash would reduce the strength of the coal gangue concrete, but increase its chloride resistance (namely decreasing the chloride migration coefficient), regardless of the water-cement ratio [57]. 


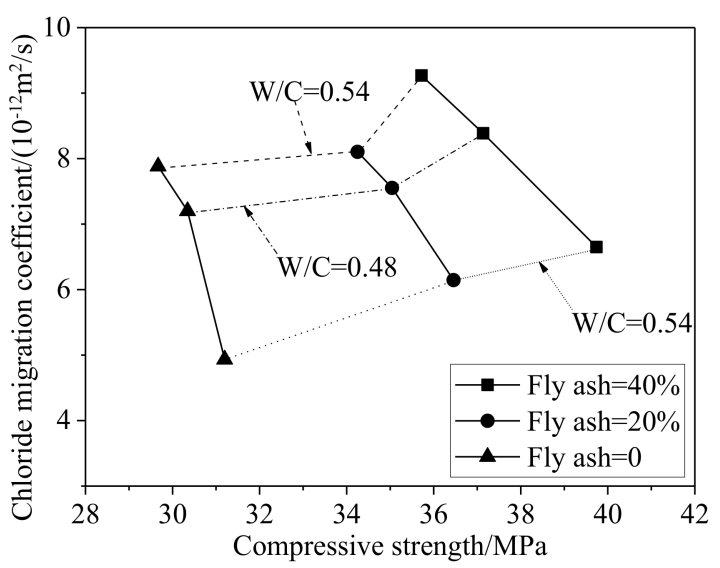

Figure 11. Relationship between chloride migration coefficient and strength of coal gangue concrete [57].

\subsection{Thermal Characteristic}

As mentioned above, increasing the CG content would normally degrade the mechanical and durability performance of the coal gangue concrete. In contrast, the porous structure of CG is beneficial for thermal insulation. Therefore, a novel type of thermal insulation coal gangue concrete using coal gangue is proposed [19]. Besides coal gangue, glazed hollow bead (GHB), nano-silica (NS), and ultra-fine slag (UFS) are also used to improve the performance of the novel concrete. As shown in Figure 12, increasing the CG content of the concrete would significantly reduce its thermal conductivity coefficient, even though the GHB content marks the maximum influence on the thermal conductivity coefficient of the concrete, while the NS and UFS content show subtle effects.

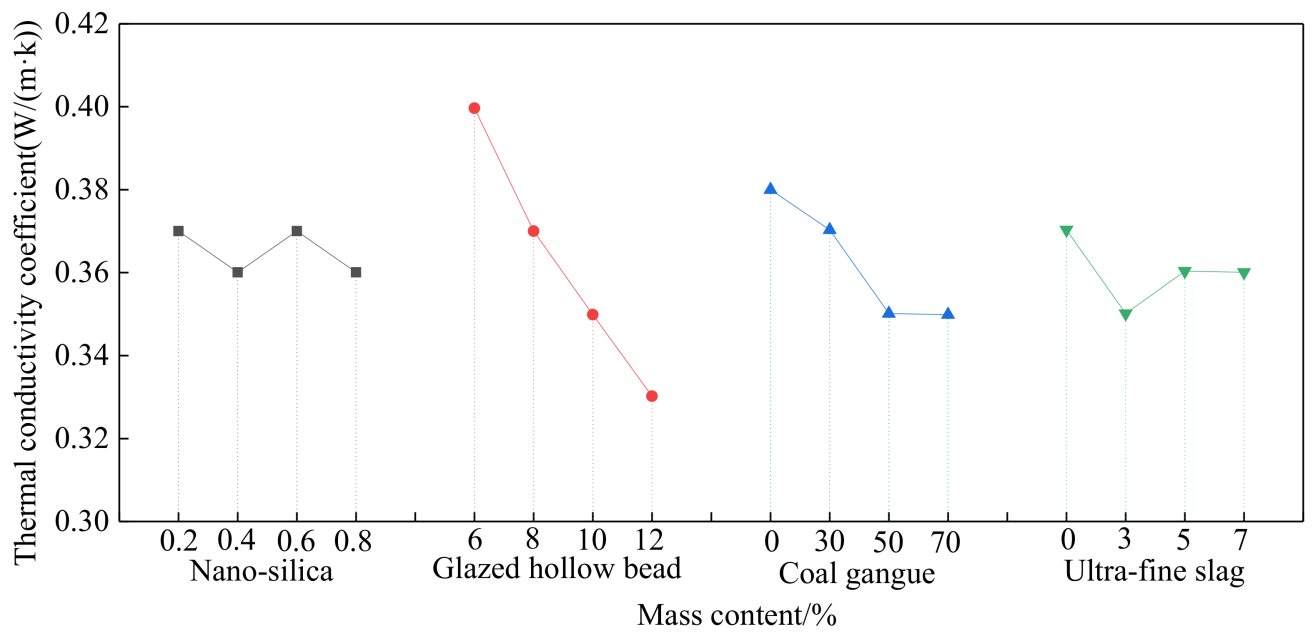

Figure 12. Thermal conductivity coefficient of the novel coal gangue concrete [19].

\section{Application of Coal Gangue Concrete}

\subsection{Reinforced Coal Gangue Concrete}

\subsubsection{Beam}

In [59-61], the mechanical performance of SCG concrete and the flexural performance of reinforced coal gangue concrete beam are both studied. As shown in Figure 13, the reduction of the ultimate moment for reinforced coal gangue concrete beams is a little larger than that of the coal gangue concrete itself, while the cracking moment of reinforced coal gangue concrete seems unrelated to the coal gangue concrete replacement ratio, which may result from the various properties of coal gangue. In general, the ultimate moment reduction of reinforced coal gangue concrete beam is below $10 \%$, which seems acceptable in practical engineering. Furthermore, [59-61] also indicate that the current design method in 
Chinese standards could be directly used to predict the flexural resistance of the reinforced coal gangue concrete beam by using the corresponding compressive strength of the coal gangue concrete.

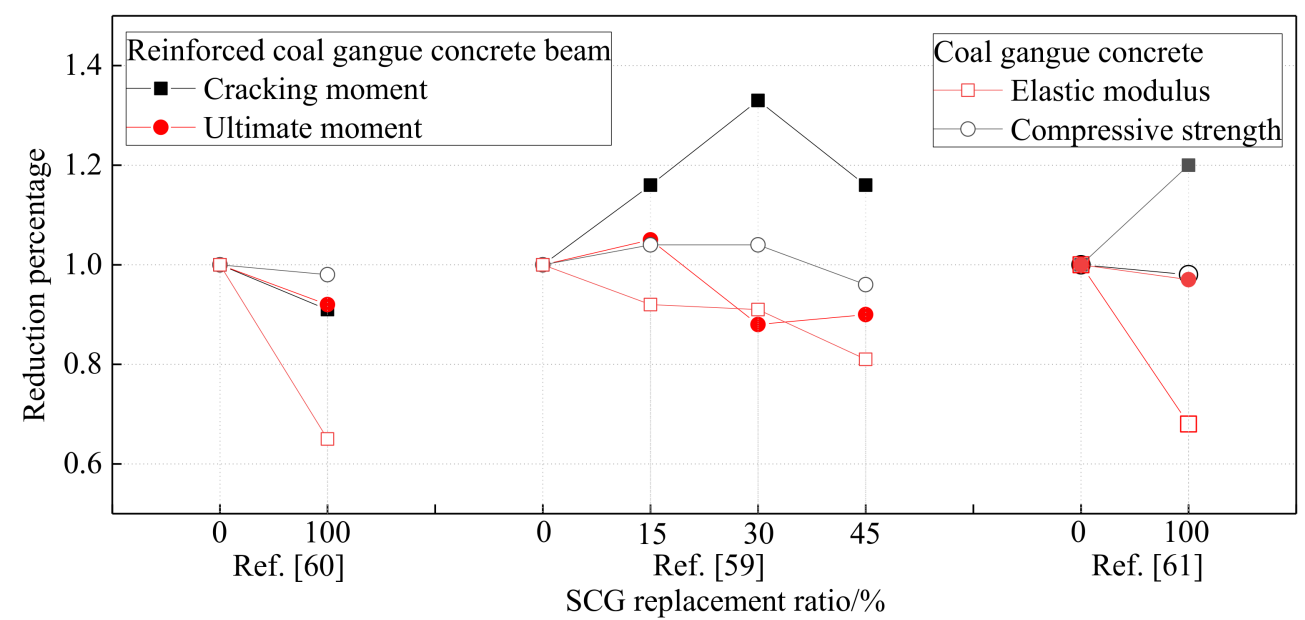

Figure 13. Flexural performance reduction of the reinforced coal gangue concrete beam.

As shown in Figure 14 [62], the compressive strength reduction of coal gangue concrete is remarkable, which results in a remarkable reduction in the shear resistance of the reinforce coal gangue concrete beam. Regardless of the CG replacement ratio, the beams show a shear-compression failure pattern. The shear resistance of reinforced coal gangue concrete beams could also be predicted by the current design method using Chinese standards.

\subsubsection{Column}

The reinforced concrete columns using RCG show similar failure patterns to the normal reinforced concrete columns under axial and eccentric compression [63], except that the cracking load of the columns is reduced by increasing the CG replacement ratio. The effects of the eccentric ratio and CG replacement ratio on the resistance reduction of the columns are shown in Figure 15. The compressive resistance of reinforced coal gangue concrete columns could be predicted by the current design method in Chinese standards. In contrast, a large coal gangue replacement and axial compression ratio is not suggested in the columns under seismic loads [64].

\subsubsection{Wall}

As shown in Figure 16, the failure pattern of coal gangue concrete shear wall under cyclic loads is similar to that of a normal concrete shear wall, even though the failure of coal gangue concrete shear wall tends to be slightly more severe when raising the CG replacement ratio $[65,66]$. About a $10 \%$ reduction in the horizontal resistance of the wall was caused when using a 100\% SCG replacement ratio, while the ultimate horizontal displacement of the wall was reduced by $3 \%$. By considering the degradation of shear resistance under cyclic loads, namely a 30\% reduction, the current design method in Chinese standards was modified for the shear resistance of coal gangue concrete wall [67]. 


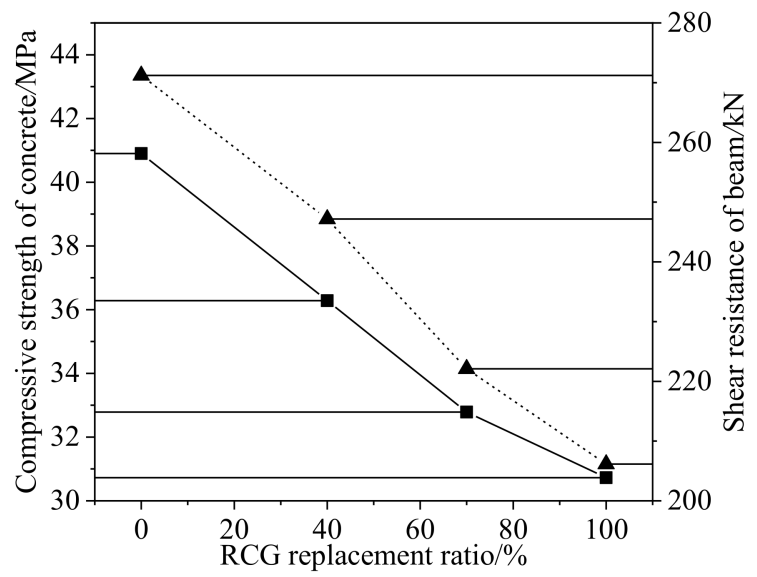

(a)

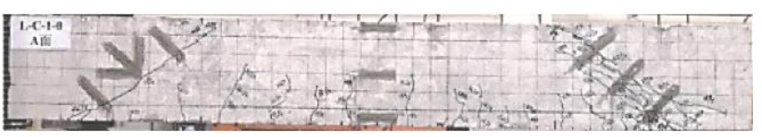

No RCG

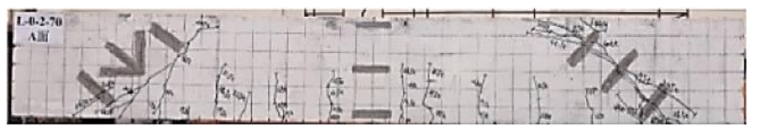

$\mathrm{RCG}=70 \%$

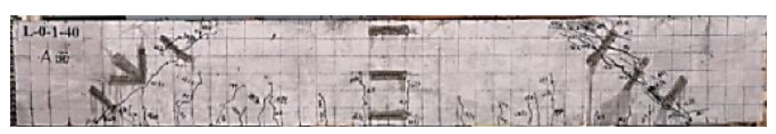

$\mathrm{RCG}=40 \%$

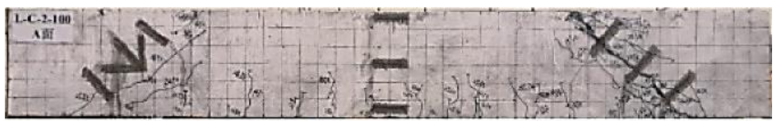

RCG $=100 \%$

(b)

Figure 14. Shear performance of a reinforced coal gangue concrete beam [62]. (a) Shear resistance reduction; (b) Shear-compression failure patterns.

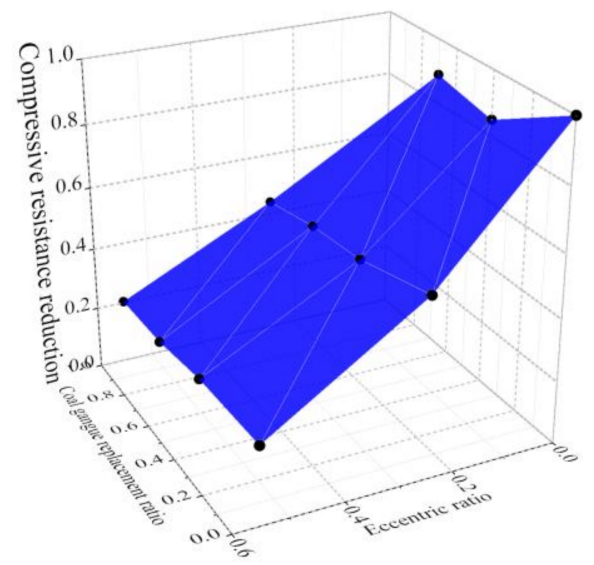

Figure 15. Compressive performance of reinforced coal gangue concrete columns.

\subsection{Coal Gangue Concrete Filled Steel Tube}

As mentioned above, the mechanical and durability performance of concrete is degraded when using coal gangue concrete. Therefore, concrete filled steel tubes (CFSTs) are an applicative configuration for using coal gangue concrete, as the external tube not only enhances the mechanical behavior of the internal core coal gangue concrete, but also protects it from the effect of severe environment [68-70]. 


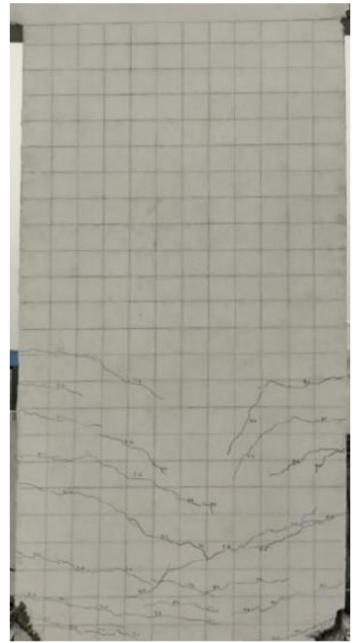

No SCG $\left(f_{\mathrm{c}}=29.2 \mathrm{MPa}\right)$

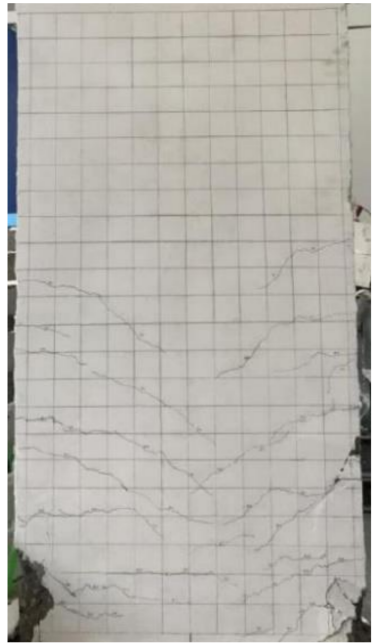

$\mathrm{SCG}=50 \%\left(f_{\mathrm{c}}=27.7 \mathrm{MPa}\right)$

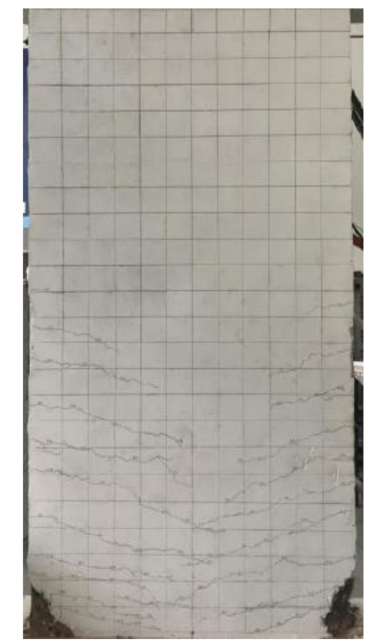

$\mathrm{SCG}=100 \%\left(f_{\mathrm{c}}=26.99 \mathrm{MPa}\right)$

Figure 16. Failure patterns of coal gangue concrete wall [65].

Similar to reinforced coal gangue concrete stubs, the failure pattern of CFST stubs with coal gangue is also barely influenced by the CG replacement ratio, regardless of the concrete grade, as shown in Figure 17a. The axial strength of CFST with coal gangue is linearly related to the RCG replacement ratio [71]. Under a 100\% replacement ratio, the axial capacity of CFST with coal gangue is reduced by $38 \%$, while the compressive strength of coal gangue concrete is reduced by $50 \%$. The current design method in Chinese standard GB50936-2014 for normal CFST was modified regarding the effect of CG replacement ratio, as follows [72]. The corresponding error of the modified method was in the range of $\pm 10 \%$. Even though this semi-empirical prediction method is proposed here for the first time, it is only valid for the CG from specific origins, as with the above-mentioned formulas regarding CG concrete.

$$
\begin{aligned}
N_{u p}^{\mathrm{CGCFST}}(r)= & \left(A_{c}+A_{s}\right)\left(1.212+\left(\frac{0.176 f_{y}}{213}+0.974\right) \xi+\left(\frac{-0.104 k_{s r}^{\mathrm{CGC}} f_{c}}{14.4}+0.031\right) \xi^{2}\right) k_{s r}^{\mathrm{CGC}} f_{c} \\
& \text { where } k_{s r}^{\mathrm{CGC}} \text { is the strength reduction factor of coal gangue concrete, } \\
& k_{s r}^{\mathrm{CGC}}=1-0.909 r_{\mathrm{CG}}+0.425 r_{\mathrm{CG}^{2}} .
\end{aligned}
$$

\subsection{Steel-Coal Gangue Concrete Composite Structure \\ 6.3.1. Wall}

Some researchers have proposed setting an internal steel plate into reinforced coal gangue concrete walls to enhance their seismic capacity [73,74], as shown in Figure 18. Even though this configuration is supposed to be beneficial, and both experimental and numerical studies have been conducted in $[73,74]$, the effect of the CG replacement ratio has not been represented in these studies, which mostly focus on the effect of the internal steel plate, rather than the coal gangue concrete. In addition, the simplified theoretical prediction for the shear resistance and the seismic model of this coal gangue concrete shear wall with internal steel plate is also not presented. 


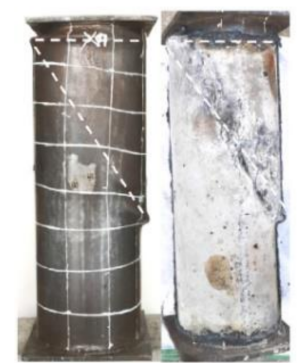

C40-No RCG

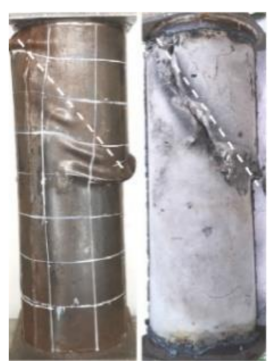

C40-100\% RCG

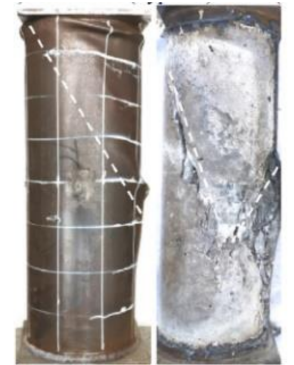

C60-No RCG

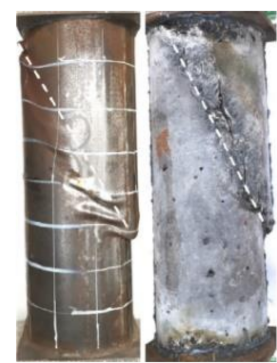

C60-100\% RCG

(a)

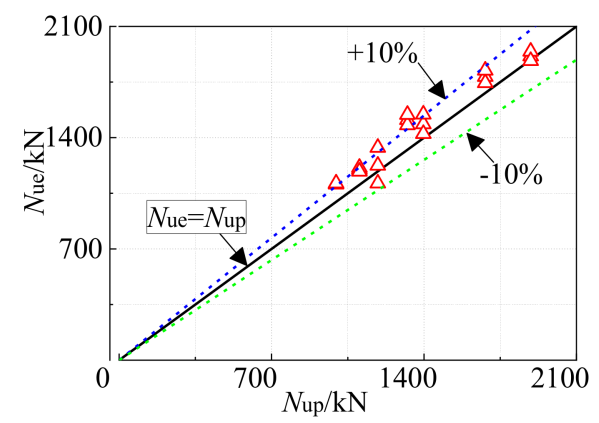

(b)

Figure 17. Compressive performance of coal gangue concrete filled steel tubes [72]. (a) Failure pattern; (b) Axial strength prediction.

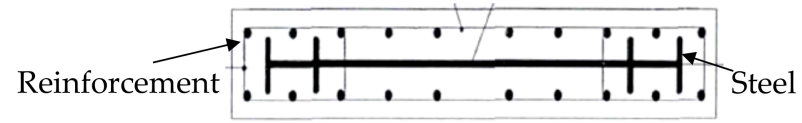

(a)

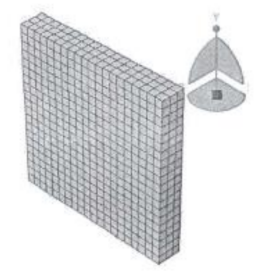

Concrete wall

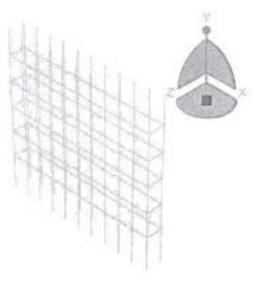

Reinforcement mesh

(b)

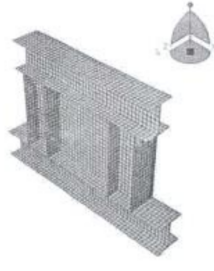

Steel plate

Figure 18. Coal gangue concrete shear wall with an internal steel plate [73,74]. (a) Profile of the tested composite wall; (b) Finite element model of the composite wall.

\subsubsection{Slab}

As a light-weight aggregate (bulk density less than $1200 \mathrm{~kg} / \mathrm{m}^{3}$ [75]), coal gangue is also preferable in concrete slabs, especially with profiled steel sheeting, namely composite slabs, as shown in Figure 19. However, the performance of the slab with coal gangue concrete and profiled steel sheeting is still limited. Some preliminary studies confirm the feasibility of using coal gangue concrete in composite slab with profiled steel sheeting, even though the deflection of the slab with coal gangue concrete is about $10 \%$ larger than that with normal concrete [76,77]. 


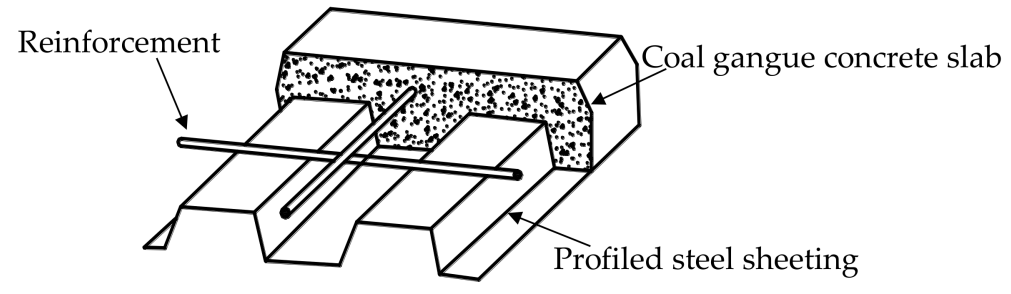

Figure 19. Composite slab with coal gangue concrete and profiled steel sheeting.

\section{Discussion and Research Gap}

Based on the above analysis, generally, the properties of coal gangue coarse aggregates are feasible for substituting natural coarse aggregates in the preparation of green concrete. The mechanical performance, durability performance, and even the thermal characteristic of the coal gangue coarse aggregate concrete have been investigated. Even though the properties of coal gangue vary according to origins, the usage of coal gangue coarse aggregate would decrease the mechanical and durability performance, but improve the thermal characteristic of the concrete. The mechanical behaviour of coal gangue concrete is generally acceptable in practical applications, while its durability is relatively poor. The proposed stress-strain models of coal gangue concrete could be used in the numerical and theoretical prediction for its mechanical performance $[77,78]$. However, these models are empirically-based, and are highly related to the properties of the local coal gangue.

In contrast, the application of coal gangue coarse concrete in structural members is relatively limited. The mechanical performance of reinforced concrete, CFST, and steel-concrete composite structures with coal gangue concrete have been investigated considering the structural members of beams, columns, and walls. In particular, most of the formulas for the load-bearing capacity prediction of these members do not even consider the influence of the CG replacement ratio $[79,80]$.

It is worthy of attention that CFST is an applicative configuration for using coal gangue concrete, even without a thorough study on its durability performance, since the external tube could protect core coal gangue concrete from the effect of severe environments. The prediction method for the axial resistance of CFST with coal gangue by directly considering the influence of the CG replacement ratio is relatively accurate and simple for practical application.

It has been found that structural concrete-based coal gangue has several issues that, need to be resolved before its usage in the structural engineering. The following research gaps have been identified.

(1) The physical properties of RCG and SCG should be investigated comparatively in particular, since they are quite crucial to the properties of coal gangue concrete. In other words, the physical change of coal gangue as a coarse aggregate in concrete mixture before and after spontaneous/artificial combustion should be compared and identified quantitatively.

(2) Even though the main content in the chemical composition of RCG and SCG is actually stable, heavy metal and organic matter leaching of RCG and SCG should be studied comparatively. More specific permission regarding heavy metal and organic matter leaching in coal gangue should be issued by governments to avoid posing environmental, health, and safety concerns.

(3) The workability of coal gangue concrete significantly varies from the gangue origins, which makes the improvement method ineffective in some cases. This phenomenon may be solved if the physical properties of coal gangue are assessed more accurately. A proper index to assess the workability of coal gangue concrete for practical use should also be proposed based on more experimental data.

(4) Even though the degradation effect of coal gangue aggregate on the mechanical properties of coal gangue concrete is obvious, the empirical stress-strain model should be validated against more data. In particular, the elastic modulus and tensile 
strength of coal gangue concrete have not been described through theoretical models, not to mention bending and creep performance and damage accumulation process.

(5) The studies on the durability performance of coal gangue concrete are directly related to the properties of the coal gangue aggregate. Therefore, the specific properties and replacement ratio of coal gangue should be considered in the prediction formulas regarding the durability performance of coal gangue concrete. More tests on the durability performance of coal gangue concrete are still needed, such as the drying and watering cycle, high temperature, abrasion resistance, and sulfate resistance.

(6) Besides the experimental and theoretical studies on the structural members with coal gangue concrete are rather limited, the durability performance of those has never been studied. Specifically, the interface bonding behavior between the steel component and coal gangue coarse aggregate concrete under the severe environment and long-term loading should be studied in detail. More design methods from formal standards should be modified by considering the properties of coal gangue for practical applications.

\section{Conclusions}

This paper has reviewed the utilization of coal gangue (CG) in green concrete as a coarse aggregate. The mechanical and durability performance of coal gangue concrete and the corresponding structural members have been analyzed from the reported literature. The main conclusions are as follows:

(1) The physical and chemical properties of rock and spontaneous-combustion coal gangue are generally suitable for being used as a coarse aggregate in green concrete, even though these properties vary from the origin. The short-term heavy metal leachability of coal gangue is also relatively weak. However, more specific permission regarding heavy metal and organic matter leaching in coal gangue should be issued by governments to avoid posing environmental, health, and safety concerns.

(2) Coal gangue concrete is not recommended to be used in subsurface structures, since its water absorption law would be changed by increasing the CG replacement ratio. The slump of coal gangue concrete with a 100\% CG content would be reduced by about $10-20 \%$. Adding fly ash, superplasticizer, and additional water are effective and simple ways to enhance the workability of coal gangue concrete. A proper index to assess the workability of coal gangue concrete for practical use should also be proposed based on more experimental data.

(3) The mechanical performance, including compressive strength, elastic modulus, and splitting tensile strength of coal gangue concrete is degraded by raising the CG replacement ratio. This degradation caused by the porous structure of CG varies significantly from the CG origin. Over-low and -high concrete grades are not suggested to be used as coal gangue aggregates, unless extra admixture or specific methods are used. The models for describing the elastic modulus, tensile strength, bending strength, and creep performance of coal gangue concrete are still needed for practical applications.

(4) The porous structure of coal gangue provides more transmission channels for air and liquid in concrete. Therefore, the influence of CG on the durability of coal gangue concrete is more remarkable than on its mechanical performance, which could be reduced by adding super-fine admixture and calcination. In contrast, the porous structure of CG is beneficial in the preparation of thermal insulation concrete. The specific properties and replacement ratio of coal gangue should be considered in the prediction formulas regarding the durability performance of coal gangue concrete.

(5) The application of coal gangue concrete in structural members is still limited. Even though the static and seismic behavior of some structural members using coal gangue concrete has been investigated, the durability of these structural members has never been reported. Specifically, the interface bonding behavior between steel component and coal gangue coarse aggregate concrete under the severe environment and longterm loading should be studied in detail. Among them, concrete filled steel tubes 
are a preferable configuration for using coal gangue concrete, regarding both the mechanical and durability performance.

Author Contributions: Conceptualization, writing-original draft preparation, S.G.; methodology, S.Z.; writing-review and editing, L.G. All authors have read and agreed to the published version of the manuscript.

Funding: This research was funded by the Youth Innovation Team of Shaanxi Universities (21JP138).

Institutional Review Board Statement: Not applicable.

Informed Consent Statement: Not applicable.Data Availability: The raw/processed data required to reproduce these findings cannot be shared at this time as the data also forms part of an ongoing study.

Conflicts of Interest: The authors declare no conflict of interest.

\section{References}

1. BP. BP Statistical Review of World Energy; BP: London, UK, 2019.

2. Zhang, Y.L.; Ling, T.C. Reactivity activation of waste coal gangue and its impact on the properties of cement-based materials-A review. Constr. Build. Mater. 2020, 234, 117424. [CrossRef]

3. Li, D.; Song, X.; Gong, C.; Pan, Z. Research on cementitious behavior and mechanism of pozzolanic cement with coal gangue. Cem. Concr. Res. 2006, 36, 1752-1759. [CrossRef]

4. Li, J.Y.; Wang, J.M. Comprehensive utilization and environmental risks of coal gangue: A review. J. Clean. Prod. 2019, $239,117946$. [CrossRef]

5. Jabłońska, B.; Kityk, A.V.; Busch, M.; Huber, P. The structural and surface properties of natural and modified coal gangue. J. Environ. Manag. 2017, 190, 80-90. [CrossRef] [PubMed]

6. Moghadam, M.J.; Ajalloeian, R.; Hajiannia, A. Preparation and application of alkali-activated materials based on waste glass and coal gangue: A review. Constr. Build. Mater. 2019, 221, 84-98. [CrossRef]

7. Huang, Y.L.; Li, J.M.; Song, T.Q.; Sun, Q.; Kong, G.; Wang, F. Microstructure of coal gangue and precipitation of heavy metal elements. J. Spectrosc. 2017, 3128549. [CrossRef]

8. Dong, Z.; Xia, J.; Fan, C.; Cao, J. Activity of calcined coal gangue fine aggregate and its effect on the mechanical behavior of cement mortar. Constr. Build. Mater. 2015, 100, 6-69. [CrossRef]

9. Cheng, Y.; Hongqiang, M.; Hongyu, C.; Jiaxin, W.; Jing, S.; Zonghui, L.; Mingkai, Y. Preparation and characterization of coal gangue geopolymers. Constr. Build. Mater. 2018, 187, 318-326. [CrossRef]

10. Ma, X.W.; Liu, J.H.; Shi, C.J. A review on the use of LWA as an internal curing agent of high performance cement-based materials. Constr. Build. Mater. 2019, 218, 385-393. [CrossRef]

11. Cong, X.; Lu, S.; Yao, Y.; Wang, Z. Fabrication and characterization of self-ignition coal gangue autoclaved aerated concrete. Mater. Des. 2016, 97, 155-162. [CrossRef]

12. Wang, Q.; Li, Z.; Zhang, Y.; Zhang, H.; Zhou, M.; Fang, Y. Influence of coarse coal gangue aggregates on elastic modulus and drying shrinkage behaviour of concrete. J. Build. Eng. 2020, 32, 101748. [CrossRef]

13. Cheng, W.H. The Influence of Argillaceous Shale Coal Gangue on Normal Temperature and High Temperature Performance of Concrete; Harbin Institute of Technology: Harbin, China, 2015.

14. Wu, X.F.; Zhou, M.; Cui, Z.L. The experiment research on concrete strength influence of self combustion coal gangue coarse aggregate. Ind. Constr. 2009, 39, 81-85.

15. Zhou, M.; Dou, Y.; Zhang, Y.; Zhang, Y.; Zhang, B. Effects of the variety and content of coal gangue coarse aggregate on the mechanical properties of concrete. Constr. Build. Mater. 2019, 220, 386-395. [CrossRef]

16. Zhu, Z.Z. The Development of Coal Gangue Concrete and Its Performance Test; Anhui University of Science and Technology: Huainan, China, 2014.

17. Duan, X.M. Study on the Micro-Structure and Physical-Mechanical Performance of Concrete with Coal Gangue as Aggregate; China University of Mining and Technology: Xuzhou, China, 2014.

18. Miao, H.Y.; Zhang, Z.P.; Gong, L.; Wang, P. College of Architecture and Civil Engineering, Taiyuan University of Technology. Experimental study on coal gangue thermal insulation glazed hollow bead concrete. Concrete 2017, 2, 152-160.

19. Zhang, Y.; Ma, G.; Liu, Y.; Li, Z. Mix design for thermal insulation concrete using waste coal gangue as aggregate. Mater. Res. Innov. 2015, 19 (Suppl. S5), 878-884. [CrossRef]

20. Zhang, J.X.; Chen, W.L.; Yang, R.J. Experimental study on basic properties of coal gangue aggregate. J. Build. Mater. 2010, $13,739-743$.

21. Bai, C.N.; Li, L.H.; Sheng, Y.; Long, G.C.; Ma, K.L. The effects of coal gangue as coarse aggregate on mechanical property of concrete. Sichuan Build. Mater. 2018, 44, 1-3.

22. Fang, Q.C. Study on preparation and properties of shale gangue concrete. Sichuan Build. Sci. 2017, 43, 107-111. 
23. Guan, X.; Qiu, J.; Song, H.; Qin, Q.; Zhang, C. Stress-strain behaviour and acoustic emission characteristic of gangue concrete under axial compression in frost environment. Constr. Build. Mater. 2019, 220, 476-488. [CrossRef]

24. Ma, H.Q.; Yi, C.; Zhu, H.G.; Dong, Z.C.; Chen, H.Y.; Wang, J.X.; Li, D.Y. Compressive strength and durability of coal gangue aggregate concrete. Mater. Rep. B 2018, 32, 2390-2395.

25. Wang, A.G.; Zhu, Y.Y.; Xu, H.Y.; Liu, K.W.; Jing, Y.; Sun, D.S. Research progress on coal gangue aggregate for concrete. Bull. Chin. Ceram. Soc. 2019, 38, 2076-2086.

26. Guo, Y.X.; Zhang, Y.Y.; Cheng, F.Q. Industrial development and prospect about comprehensive utilization of coal gangue. CIESC J. 2014, 65, 2443-2453.

27. Wang, C.; Ni, W.; Zhang, S.-Q.; Wang, S.; Gai, G.-S.; Wang, W.-K. Preparation and properties of autoclaved aerated concrete using coal gangue and iron ore tailings. Constr. Build. Mater. 2016, 104, 109-115. [CrossRef]

28. Koshy, N.; Dondrob, K.; Hu, L.; Wen, Q.; Meegoda, J.N. Synthesis and characterization of geopolymers derived from coal gangue, fly ash and red mud. Constr. Build. Mater. 2019, 206, 287-296. [CrossRef]

29. Frías, M.; de Rojas, M.I.S.; García, R.; Valdés, A.J.; Medina, C. Effect of activated coal mining wastes on the properties of blended cement. Cem. Concr. Compos. 2012, 34, 678-683. [CrossRef]

30. Sun, Z.H.; Liu, K.P.; Wang, M.Q.; Wang, Z.M.; Yang, F.F. Study on activation properties of spontaneous combustion coal gangue. J. Build. Mater. 2013, 16, 497-502.

31. Wang, J.; Qin, Q.; Hu, S.; Wu, K. A concrete material with waste coal gangue and fly ash used for farmland drainage in high groundwater level areas. J. Clean. Prod. 2016, 112, 631-638. [CrossRef]

32. Guan, X.; Chen, J.; Qiu, J.; Gao, Y.; Gao, J. Damage evaluation method based on ultrasound technique for gangue concrete under freezing-thawing cycles. Constr. Build. Mater. 2020, 246, 118437. [CrossRef]

33. Chen, Y.W.; Sun, Q.; Wang, N.; Niu, W.Y. Experimental study on the spontaneous combustion coal gangue concrete. Concrete 2014, 10, 63-65.

34. Zhang, Y.; Wang, Q.; Zhou, M.; Fang, Y.; Zhang, Z. Mechanical properties of concrete with coarse spontaneous combustion gangue aggreagate (SCGA): Experimental investigation and prediction methodology. Constr. Build. Mater. 2020, $255,119337$. [CrossRef]

35. Zhu, K. Study on performance of lightweight aggregate concrete with fly ash and gangue. Railw. Eng. 2014, 3, 118-121.

36. Li, Y.J.; Yan, X.P.; Guo, R.Q.; Zhou, M. Study on the gradual loss in slump of the spontaneous combustion coal gangue fulllightweight concrete mixture. Bull. Chin. Ceram. Soc. 2013, 32, 727-731.

37. Zhou, M.; Wang, Q.; Mu, S. The effects on workability of concrete mixture of spontaneous combustion coal gangue coarse aggregate characteristics. Non-Met. Mines 2013, 36, 8-11.

38. Chen, B.P. Strength of gangue concrete. Ind. Constr. 1994, 7, 29-32.

39. Wang, Z.S.; Zhao, N. Properties of steel fiber reinforced coal gangue coarse aggregate concrete. Wuhan Univ. J. Nat. Sci. 2014, 19, 262-268. [CrossRef]

40. Yang, Q.B.; Lu, M.X.; Luo, Y.B. Effects of surface-activated coal gangue aggregates on properties of cement-based materials. J. Wuhan Univ. Technol.-Mater. Sci. Ed. 2013, 28, 1118-1121. [CrossRef]

41. Cui, Z.L.; Li, J. Effect of coarse aggregate with different water absorption on strength and drying shrinkage of concrete. Bull. Chin. Ceram. Soc. 2016, 35, 2396-2399.

42. Cui, Z.L.; Hao, J.L.; Chen, L.; Lan, Y. Experimental study on strength and drying shrinkage crack of spontaneous combustion gangue concrete. Non-Met. Mines 2015, 38, 76-78.

43. Wang, Q.; Zhao, Z.Q.; Liu, Y.Q.; Liu, S. Research on shrinkage performance of coal gangue concrete. Concrete 2015, 10, 68-70.

44. Qiu, J.S.; Zheng, J.J.; Guan, X.; Gu, S.; Pan, D.; Zhang, C. Capillary water absorption properties of coal gangue concrete under freezing-thawing circumstance. J. Build. Mater. 2017, 20, 881-885.

45. Zhang, J.X.; Chen, W.L.; Jin, S.S.; Chen, C.-Z.; Yang, R.-J. Investigation on durability of coal gangue aggregate concrete. J. Beijing Univ. Technol. 2011, 37, 116-125.

46. Li, Y.J.; Han, J.J.; Xing, Y.; Yan, X.P.; Zhang, X. Research on the freezing and thawing cycle test of coal gangue aggregate concrete. Concrete 2013, 12, 100-103.

47. Zhou, M.; Zhao, H.M.; Wang, R.; Chen, C.; Qu, H.-L. Effect of admixture on impermeability and frost resistance of spontaneous combustion gangue sand-lightweight concrete. Bull. Chin. Ceram. Soc. 2015, 34, 131-137.

48. Zhang, X.D.; Li, Q.W.; Song, Y. Study of anti-freezing agent on frost resistance of coal gangue concrete mixing with water reducers. Non-Met. Mines. 2016, 39, 48-51.

49. Zhu, K.; Yuan, S.L.; Ma, X.W. Study of the road performance of fiber reinforced coal gangue light-weight aggregate concrete. China Concr. Cem. Prod. 2015, 6, 58-61.

50. Sun, J.Y.; Lu, L.G. Coupled effect of axially distributed load and carbonization on permeability of concrete. Constr. Build. Mater. 2015, 79, 9-13. [CrossRef]

51. Chen, Y.W.; Ding, Z.Y.; Zhu, J.S.; Sun, X.W. Experimental study on the spontaneous combustion coal gangue concrete. Concrete 2015, 5, 87-89.

52. Li, Q.W.; Zhang, X.D.; Li, G.X.; Li, Y.; Zhang, J. Study on carbonation depth of spontaneous combustion coal gangue lightweight aggregate concrete. Chin. J. Environ. Eng. 2016, 10, 2616-2620. 
53. Li, Y.J.; Xing, Y.; Han, J.J.; Cao, S. Experimental research on gas permeability and carbonation resistance of coal gangue aggregates. Non-Met. Mines 2016, 39, 17-20.

54. Yi, C.; Ma, H.Q.; Zhu, H.G.; Dong, Z.C.; Su, Z.J.; Zhang, Y.T.; Chu, Z. Investigation on anti-carbonation performance of coal gangue coarse aggregate concrete. J. Build. Mater. 2017, 20, 787-793.

55. Zhou, M.; Tian, B.Y.; Wang, Q.; Mou, S.; Pu, B.C. Experimental study on the influence of spontaneous combustion gangue coarse aggregate on sand lightweight concrete performance. Bull. Chin. Ceram. Soc. 2013, 32, 2231-2237.

56. Wang, Q.; Liu, S.; Wang, J.B.; Li, M.; Liu, Y. Research on resistance to chloride ion of the coal gangue coarse aggregate concrete. Concrete 2016, 8, 36-38.

57. Li, Y.J.; Xing, Y. Experiment study on chloride ion penetration of coal gangue concrete. Non-Met. Mines 2016, 39, 11-13.

58. Zhou, M.; Li, G.N.; Zhang, Q.; Cui, H. Study on application of spontaneous combustion coal gangue aggregate in ready-mixed concrete. J. Build. Mater. 2015, 18, 830-835.

59. Feng, J.X. Coal Gangue Type of Self-Compacting Concrete Beam Bending Performance Test Research; Yianbian University: Yianbian, China, 2017.

60. Wang, Q.H.; Li, Z.; Zhou, M.; Zhang, Y.Z. Effects of spontaneous-combustion coal gangue aggregate replacement ratio on flexural behavior of reinforced concrete beams. J. Build. Struct. 2020, 41, 64-74.

61. Li, G.N. Study of Flexural Behavior on Spontaneous Combustion Gangue Aggregate Reinforced Concrete Beam; Liaoning Technical University: Liaoning, China, 2015.

62. Bai, G.L.; Zhu, C.; Wang, J.W.; Li, X.X.; Liu, H.; Lu, G.K. Experimental study on shear behavior of coal gangue concrete beams. J. Build. Struct. 2020, 41, 49-55.

63. Liu, H.Q. Experimental Study on Bearing Capacity of Coal Gangue Concrete Column; Xi'an University of Architecture and Technology: Xi'an, China, 2019.

64. Li, Y.J.; Yan, X.P.; Zhang, X.; Geng, X.; Zhang, J. Experimental research on seismic behavior of reinforced concrete column composed of coal gangue aggregate. J. China Coal Soc. 2013, 38, 1006-1011.

65. Wang, S.X. Experimental Study on Seismic Performance of Coal Gangue Concrete Shear Wall under Horizontal Reciprocating Load; Liaoning Technical University: Liaoning, China, 2020.

66. Zhuang, Y.Z. Mechanical properties of self-combusted gangue reinforced concrete shear walls under low-cyclic load. J. Zhejiang Univ. 2000, 34, 325-330.

67. Tan, X.M.; Guo, M.H.; Wang, F.M. Earthquake-resistant behavior of low-rise self-combusted gangue reinforced concrete shear wall. J. South China Univ. Technol. Nat. Sci. 1999, 27, 67-73.

68. Li, G.C.; Liu, Z.Y.; Yang, L.Z. The constitutive equation and strength criterion on core concrete of gangue concrete filled steel tube. J. Northeast. Univ. Nat. Sci. 2002, 23, 64-66.

69. Li, G.C.; Xu, Z.; Zhang, C.Y. Finite element analysis of gangue concrete-filled steel tubular beam-columns. J. Shenyang Jianzhu Univ. Nat. Sci. 2010, 26, 1052-1057.

70. Zhang, N.; Zheng, C.; Zhao, Z.; Yang, B. Experimental investigations on compression behavior of GFRP-coal gangue concrete-steel tubular columns. J. Build. Mater. 2020, 9, 1-10.

71. Zhang, H.B. Experimental Study on Bearing Capacity of Self Compacting Concrete-Filled Steel Pipe Short Column under Axial Compression; Yanbian University: Yanbian, China, 2018.

72. Gao, S.; Zhao, G.; Guo, L.; Zhou, L.; Yuan, K. Utilization of coal gangue as coarse aggregates in structural concrete. Constr. Build. Mater. 2020, 268, 121212. [CrossRef]

73. Peng, Q. Experimental Study on the Mechanical Properties of the Coal Gangue Concrete Shear Wall with Internal Steel Plate; Shenyang Jianzhu University: Shenyang, China, 2015.

74. Liu, H. Study on Seismic Performance of a Steel Plate Gangue Concrete Composite Shear Wall; Shenyang Jianzhu University: Shenyang, China, 2015.

75. GB/T 17431.1-2010. Lightweight Aggregates and Its Test Methods-Part 1: Lightweight Aggregates; Standardization Administration of China: Beijing, China, 2010.

76. Li, G.C.; Chang, C.; Qu, Z.S. Mechanics function of composite slab with gangue concrete and profiled sheeting. J. Liaoning Tech. Univ. 2003, 22, 61-63.

77. Li, Z.H. Finite Element Analysis of Profiled Steel Sheet-Coal Gangue Lightweight Aggregate Concert Composite Slabs; Taiyuan University of Technology: Taiyuan, China, 2008.

78. Javed, M.F.; Amin, M.N.; Shah, M.I.; Khan, K.; Iftikhar, B.; Farooq, F.; Aslam, F.; Alyousef, R.; Alabduljabbar, H. Applications of gene expression programming and regression techniques for estimating compressive strength of bagasse ash based concrete. Crystals 2020, 10, 737. [CrossRef]

79. Rehman, S.K.U.; Kumarova, S.; Memon, S.A.; Javed, M.F.; Jameel, M. A review of microscal, rheological, mechanical, thermoelectrical and piezoresistive properties of graphene based cement composite. Nanomaterials 2020, 10, 2076.

80. Rehman, S.K.U.; Ibrahim, Z.; Memon, S.A.; Javed, M.F.; Khushnood, R.A. A sustainable graphene based cement composite. Sustainability 2017, 9, 1229. [CrossRef] 